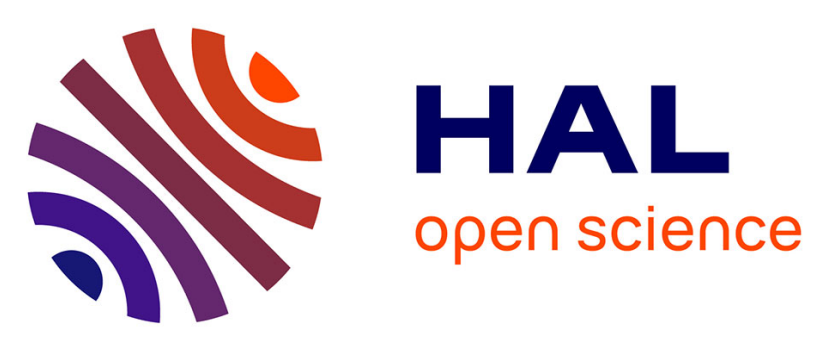

\title{
Harnessing Composition of Iron Oxide Nanoparticle: Impact of Solvent-Mediated Ligand-Ligand Interaction and Competition between Oxidation and Growth Kinetics
}

Geoffrey Cotin, Francis Perton, Corinne Petit, Sécou Sall, Céline Kiefer, Valentin Begin, Benoit Pichon, Christophe Lefèvre, Damien Mertz, Jean-Marc Greneche, et al.

\section{To cite this version:}

Geoffrey Cotin, Francis Perton, Corinne Petit, Sécou Sall, Céline Kiefer, et al.. Harnessing Composition of Iron Oxide Nanoparticle: Impact of Solvent-Mediated Ligand-Ligand Interaction and Competition between Oxidation and Growth Kinetics. Chemistry of Materials, 2020, 32 (21), pp.9245-9259. 10.1021/acs.chemmater.0c03041 . hal-03008879

\section{HAL Id: hal-03008879 https://hal.science/hal-03008879}

Submitted on 9 Dec 2020

HAL is a multi-disciplinary open access archive for the deposit and dissemination of scientific research documents, whether they are published or not. The documents may come from teaching and research institutions in France or abroad, or from public or private research centers.
L'archive ouverte pluridisciplinaire HAL, est destinée au dépôt et à la diffusion de documents scientifiques de niveau recherche, publiés ou non, émanant des établissements d'enseignement et de recherche français ou étrangers, des laboratoires publics ou privés. 
Harnessing composition of iron oxide nanoparticle: impact of solvent mediated ligand-ligand interaction and of competition between oxidation and growth kinetics

Geoffrey Cotin $^{1,2}$, Francis Perton ${ }^{1,2}$, Corinne Petit ${ }^{3}$, Sécou Sall ${ }^{3}$, Céline Kiefer $^{1,2}$, Valentin Begin ${ }^{1,2}$, Benoit Pichon ${ }^{1,2}$, Christophe Lefevre ${ }^{1,2}$, Damien Mertz ${ }^{1,2}$, Jean-Marc Greneche $^{4}$, Sylvie Begin-Colin ${ }^{1,2^{*}}$

${ }^{1}$ Université de Strasbourg, CNRS, Institut de Physique et Chimie des Matériaux de Strasbourg, UMR 7504, F-67034 Strasbourg, France

${ }^{2}$ Labex CSC, Fondation IcFRC/Université de Strasbourg, 8 allée Gaspard Monge BP 70028 F - 67083 Strasbourg Cedex.

${ }^{3}$ Institut de chimie et procédés pour l'énergie, l'environnement et la santé (ICPEES) UMR7515 25 rue du loess 67087 Strasbourg cedex

${ }^{4}$ Institut des Molécules et Matériaux du Mans IMMM UMR CNRS 6283, Université du Maine, Avenue Olivier Messiaen, 72085 Le Mans Cedex 9, France

Corresponding authors: sylvie.begin@unistra.fr 


\section{Abstract}

The composition of metal oxide nanoparticles is of great importance for their applications because defects and/or deviation from stoechiometry strongly affect their physical properties. We report here on the crucial role of synthesis parameters such as solvent, ligand and iron precursors on the composition of spinel iron oxide nanoparticles synthesized by the thermal decomposition method. At first, the investigation of the thermal decomposition of iron stearates bearing either two or three stearate chains by thermogravimetric analysis, IR spectroscopy and Mössbauer spectrometry as a function of temperature and syntheses with only oleic acid and iron stearate confirmed that the composition of the first nuclei is wüstite $\mathrm{Fe}_{1-\mathrm{x}} \mathrm{O}$. The synthesis of nanoparticles with high sizes requires the use of very high boiling point solvents to ensure an effective growth step. We observed that, when the grain growth and oxidation kinetics are similar, nanoparticles with a spinel composition and quite no defects are produced. An oxidation rate slower than the nuclei growth rate favours the formation of core-shell $\mathrm{Fe}_{1-\mathrm{x}} \mathrm{O} @ \mathrm{Fe}_{3-\mathrm{x}} \mathrm{O}_{4} \quad \mathrm{NPs}$. The oxidation kinetics is shown to be influenced by surfactant and solvent natures. Indeed, surfactants such as oleic acid form a dense monolayer at the nuclei surface which oxidation kinetics will depend on this monolayer permeability. Temperature, solvents with high surfactant affinity, deprotonated surfactants or decomposition products of solvents affect the monolayer stability and thus the nanoparticle composition. The solvents' nature and solvent mediated ligand-ligand interactions are thus evidenced to be important parameters to control the formation of defectsfree and stoechiometric oxide nanoparticles. 


\section{INTRODUCTION}

Metal oxide nanoparticles (NPs) exhibit unique physical and chemical properties due to their size, a high density of corner or edge surface sites and their composition[1,2]. Indeed, such parameters may affect the surface reactivity, electronic structure and catalytic properties of NPs and induce high surface free energy, surface non-stoichiometry, structural perturbations (changes in lattice parameters), spin canting or stabilization of phases not observed in the bulk state. Metal oxide NPs find applications in a broad range of fields linked mostly to the nanotechnologies. Current challenges lie in the fine tuning of their physical properties by mastering their size[3-5] and shape[6-8]. Yet, volume and surface defects along with the composition of NPs are crucial parameters to control as they strongly trigger their physical properties[9-11].

Indeed, metal oxide semiconductors would present an optical band gap energy with an inverse squared dependence of the primary particle size if quantum confinement dominates the energy behavior of the band gap. However, some deviations are observed, as in the case of $\mathrm{Cu}_{2} \mathrm{O}[12]$ or $\mathrm{CeO}_{2}[13]$, and are attributed to typical point defects in nanostructured oxides: oxygen or cation vacancies and/or the presence of foreign species, like $\mathrm{Cu}^{2+}$ and $\mathrm{Ce}^{3+}$. It is not clear if the presence of these oxidation states is intrinsic to the nanostructure or if it results from the specific procedure of preparation. However, depending on the method of preparation, and particularly of the Ce oxidation state of the precursor salt, the content of oxygen vacancies and concomitant presence of $\mathrm{Ce}^{3+}$ in a ceria nanoparticle can change[2]. The oxygen vacancies and defects present in ceria nanoparticles can lead to special electronic properties, introducing electronic states within the band gap of the oxide[2,14].

For other metal oxides, such as $\mathrm{SnO}_{2}[15]$ or $\mathrm{ZrO}_{2}[16]$, surface effects and, particularly, nonstoichiometry related to the preparation method are also critically 
important for very low particle size and produce characteristic features in their UVvisible spectrum. Zinc oxide is actually one of the most important investigated semiconductor oxide but chemical defects also strongly influence their properties[17,18]. Defect-rich zinc oxide species was obtained under kinetically controlled conditions of $\mathrm{ZnO}$ formation by the temperature controlled thermolysis of molecular organometallic precursors. Under certain conditions (increased thermolysis temperature or rate), $\mathrm{ZnO}$ with high microstructural strain, high content of oxygen vacancies, and particular content of heteroatom impurities were obtained.

Identifying and understanding the role of the synthesis parameters on the composition and the defect in the metal oxide NPs is then preeminent for the control of physical properties of NPs. To the best of our knowledge, very few papers[19,20] deal with such effect of synthesis parameters (solvent, ligands, nature of precursors) on the synthesis mechanims and thus on composition of oxide nanoparticles.

By taking advantage of our expertise in iron oxide nanoparticles (IONPs) synthesis $[8,11,21,22]$ and also on the large amount of published works on IONPs, we have studied the dependence of the oxide composition and defects on the synthesis parameters. IONPs display broad range of applications [23] and in particular, are commercialized as contrast agents for MRI and when their size is $\sim 20$ $\mathrm{nm}$, they may provide also promising therapy by magnetic hyperthermia. The control of the IONPs size and composition is crucial to ensure adapted magnetic properties and so high heating power by magnetic hyperthermia.

However, it has been shown that equivalent NPs (size, shape ...) synthesized by different methods often display different magnetic properties [11,24-27]. Among the different synthesis methods, the thermal decomposition was demonstrated to be very effective to tune the size, shape and composition of NPs[28],-[29]. 
Nevertheless, whatever the synthesis methods, IONPs always present a saturation magnetisation lower than that of the bulk phase. This was explained by the presence of size-dependent surface and volume spin canting and also by a difficult control of the composition[11,30]. Indeed, $\mathrm{Fe}_{3-\mathrm{x}} \mathrm{O}_{4} \mathrm{NPS}$ are more or less oxidized depending on their size[11] with a composition close to maghemite's one for NPs with size smaller than $8 \mathrm{~nm}$ which contributes to lower their saturation magnetization. In particular, synthesis conditions, to obtain anisotropic or larger NPs, lead often to NPs displaying a core shell $\mathrm{Fe}_{1-\mathrm{x}} \mathrm{O} @ \mathrm{Fe}_{3-\mathrm{x}} \mathrm{O}_{4}$ composition $[6,21,31]$. Their anomalous magnetic properties (reduced saturation magnetization, high-field susceptibility, and exchange bias) are also affected by the presence of oxidationinduced defects $[31,32]$.

When working with the thermal decomposition method, the nature and amount of ligands and the temperature applied are the parameters that are commonly modified in order to control the NPs' size and shape $[33,34]$. Indeed, the thermal decomposition process, which consists inthe thermal decomposition of an iron precursor in an organic solvent in presence of surfactants (often oleic acid), ensures a separation of nucleation and growth steps which is the key factor to obtain NPs with a narrow size distribution. The NPs size may be tuned by adjusting the nature and boiling point of solvent when for the shape control, the nature of added ligands and the heating rate are important parameters. In fact, very few studies focused on understanding of the impact of the precursors's nature[35,36] or else of solvents [37] on the NPs composition and defects.

Different iron precursors have been used in the thermal decomposition method: iron oleate[21,31,38-42], iron acetylacetonate[43-45], iron pentacarbonyl[46,47]. Nevertheless, only few reports indicate a strong role on the NPs characteristics. Bronstein et al evidenced an effect of washing and aging conditions of iron oleate[35] and with alkyl chains' length[36] on the IONPs size and shape. Hufschmid 
et al.[48] also demonstrated that some precursor will be more suited for the IONPs synthesis of specific size range. Recently, the critical roles of the precursor nature and water content were underlined to control the size and shape of IONPs[22]. The effect of the solvent is mostly related to its boiling point and the higher it is, the larger the NPs diameter will be. However, we demonstrated that the solvent's nature (e.g. its polarity) may also affect the NPs size by affecting the precursor's thermal stability[11]. High polar organic solvent would favour the thermal decomposition of large amount of precursor inducing thus the germination of small nuclei with less monomer available for the grain growth step: small sized NPs are thus obtained. Some evidences hint at a major role of the solvent on the composition especially when it comes to the synthesis of nanocubes. The protocol of Kovalenko et al.[49], which uses a mixture of sodium oleate and oleic acid as ligands in alkenes, leads to core-shell $\mathrm{Fe}_{1-\mathrm{x}} \mathrm{O} @ \mathrm{Fe}_{3-\mathrm{x}} \mathrm{O}_{4}$ nanocubes when Pellegrio et al. [3] synthesized homogeneous $\mathrm{Fe}_{3-\mathrm{x}} \mathrm{O}_{4}$ cubes in a mixture of dibenzylether and squalane. Further studies are needed to better understand which parameters act on the NPs composition.

Here, we have demonstrated experimentally that the nuclei composition is the wustite one and then showed that the core-shell composition is obtained when the grain growth kinetics is faster than the oxidation kinetics. Ligand-ligand interactions on the nuclei surface as well as the temperature and nature of the solvent affect the oxidation kinetics.

\section{Experimental section}

\section{II.1 Synthesis conditions of iron stearates}

Iron stearate (II) and (III) were prepared by precipitation of sodium stearate and ferrous chloride or ferric chloride salts in an aqueous solution as previously reported[6,22].

\section{II.2 Synthesis conditions of NPs}


Iron oxide nanospheres (NS) with a mean diameter of around $10 \mathrm{~nm}$ are synthesized from an already reported reproducible protocol[11], which consists in the thermal decomposition of the iron stearate in the presence of oleic acid (OA, 99\%, Alfa Aesar) in dioctylether (OE, 99\%, Sigma). The as-synthesized iron stearate (1.38 $\mathrm{g}$ for FeSt2 and $2 \mathrm{~g}$ for FeSt3, $2.2 \mathrm{mmol}$ in iron) is mixed with OA (1.24 $\mathrm{g}, 4.4$ $\mathrm{mmol}$ ) in $20 \mathrm{~mL}$ of OE in a two-neck RBF. The mixture is stirred and heated at 120 ${ }^{\circ} \mathrm{C}$ for $1 \mathrm{~h}$ without reflux condenser to dissolve the reactants and remove the volatile molecule residues. The cooler is then connected to the flask, and the solution is heated to the boiling temperature $\left(\sim 290{ }^{\circ} \mathrm{C}\right)$ with heating rate of 5 ${ }^{\circ} \mathrm{C} / \mathrm{min}$ and heated to reflux for $2 \mathrm{~h}$ under air (the setting temperature is $320^{\circ} \mathrm{C}$ allowing to reach $290^{\circ} \mathrm{C}$ as reaction temperature). After it cooled to RT, a black suspension is obtained. This solution is solubilized in $10 \mathrm{~mL}$ of chloroform. The NPs are then precipitated by the addition of an excess of acetone the first time and then washed three times with chloroform and acetone at a ratio of 1:4 at $14000 \mathrm{rpm}$ for $5 \mathrm{~min}$ by centrifugation. The NPs can finally be suspended in $50 \mathrm{~mL}$ of tetrahydrofuran (THF).

For the synthesis of NPs with a mean size around $20 \mathrm{~nm}$ : iron (III) stearate $\left(\mathrm{FeSt}_{3}\right)$ is decomposed in the presence of oleic acid (OA, 99\%, Alfa Aesar) in squalane (SQ, 96\%, Sigma Aldrich) with or without Dibenzylether (DBE, 99\%, Acros Organic) or dioctylether. The as-synthesized iron (III) stearate $(1.85 \mathrm{~g}, 2 \mathrm{mmol})$ is mixed with OA (1.89 $\mathrm{g}, 6.7 \mathrm{mmol})$ in SQ $(15.8 \mathrm{~g}, 19.5 \mathrm{ml})$ and/or mixed with DBE $(0.53 \mathrm{~g}, 0.5 \mathrm{ml})$ or OE $(5-15 \mathrm{ml}$, cf. Table 2$)$ in a two-neck RBF. The mixture was heated under stirring to $120{ }^{\circ} \mathrm{C}$ and kept at this temperature for $60 \mathrm{~min}$ without reflux condenser in order to dissolve the reactants and remove water residues. The condenser was then connected to the flask and the solution heated to $330{ }^{\circ} \mathrm{C}$ or 335 ${ }^{\circ} \mathrm{C}\left(5^{\circ} \mathrm{C} / \mathrm{min}\right)$ (depending on the solvents mixture) and kept under reflux for $60 \mathrm{~min}$ under air. In these syntheses, the setting temperature was $360^{\circ} \mathrm{C}$ for all 
experiments performed in this work. After cooling to RT, a black and viscous suspension was obtained which was then solubilized in chloroform (10 ml). The NPs were precipitated by addition of an excess of acetone and washed three times with chloroform and acetone at a ratio of 1:4 at $14000 \mathrm{rpm}$ for $5 \mathrm{~min}$ by centrifugation. The NPs were resuspended in THF $(50 \mathrm{ml})$ and stored until further use.

\section{II.3 Characterization techniques}

NPs were characterized by transmission electron microscopy (TEM) with a JEOL 2100 microscope operating at $200 \mathrm{kV}$ (point resolution $0.18 \mathrm{~nm}$ ). The size distribution of NPs was calculated from the size measurements of at least 300 nanoparticles using ImageJ software.

Thermogravimetric analysis (TGA) measurements were performed on dried powder samples from 20 to $600{ }^{\circ} \mathrm{C}$ at $5{ }^{\circ} \mathrm{C} / \mathrm{min}$ under air by using an SDJ Q600 apparatus. The X-ray diffraction (XRD) pattern was recorded at room temperature with a Bruker D8 Advance diffractometer equipped with a monochromatic copper radiation source $(\mathrm{K} \alpha=0.154056 \mathrm{~nm})$ and a Lynx-Eye detector in the $27-65^{\circ}(2 \theta)$ range with a scan step of $0.03^{\circ}$. High-purity silicon powder ( $a=0.543082 \mathrm{~nm}$ ) was systematically used as an internal standard. Profile matching refinements were performed through the Fullprof program[50] using Le Bail's method[51] with the modified ThompsonCox-Hasting (TCH) pseudo-Voigt profile function.

${ }^{57} \mathrm{Fe}$ Mössbauer spectra were performed at $300 \mathrm{~K}$ and $77 \mathrm{~K}$ using a conventional constant acceleration transmission spectrometer with a ${ }^{57} \mathrm{Co}(\mathrm{Rh})$ source and a bath cryostat where the sample chamber is under He atmosphere. Further spectra have been obtained using a homemade cryofurnace where the powdered sample is maintained under vacuum (about $10^{-6}$ ), whatever the temperature ranged from $77 \mathrm{~K}$ up to $673 \mathrm{~K}$. The spectra were fitted thanks to the MOSFIT program[52] involving quadrupolar components with Iorentzian lines while a $\rightarrow \boxminus$ Fe foil was used as the 
calibration sample. The values of isomer shift are quoted relative to that of $\alpha$-Fe at $300 \mathrm{~K}$.

For IR with temperature, IR samples were prepared using dry potassium bromide $(\mathrm{KBr})$. A precise mass of precalcined sample is mixed in a mortar at 3wt\% with $\mathrm{KBr}$. This dilution prevents saturation of signals. The powder sample is next placed in the IR reaction chamber. The chamber is closed and helium or air is introduced $(5 \mathrm{~mL} / \mathrm{min})$. A ramp of temperature of $2^{\circ} \mathrm{C} / \mathrm{min}$ is applied until the temperature reach $440^{\circ} \mathrm{C}$.

\section{RESULTS}

The thermal decomposition process using iron oleate precursor, popularized by Hyeon[39], is an efficient method to synthesize IONPs with a narrow size distribution due to the possible separation of germination and growth steps in this synthesis process. They developped the heating up of iron (III) oleate as iron precursor in a high boiling point solvent in presence of surfactant (commonly oleic acid). This method is very interesting as it allows synthesizing IONPs with various sizes and shapes $[11,43,53]$. Yet, troubles with NPs synthesis reproducibility with this process have been reported, partly due to an ageing of iron (III) oleate and its hydration with time $[11,20,31,33]$. We developed the NPs synthesis using a commercial iron stearate precursor and obtained reproducible results in the standard synthesis of $10 \mathrm{~nm}$ NPs for long years. However, we once faced impurities problems with one commercial iron stearate batch and thus decided to elaborate "in house"/"homemade" iron stearates[22]. As iron oleate is constituted of three oleate chains and the commercial iron stearate of two stearate chains, iron stearates bearing either two or three stearate chains (named $\mathrm{FeSt}_{2}$ and $\mathrm{FeSt}_{3}$ respectively) were synthesized by coprecipitation in water[22]. The investigation of both precursors thermal decomposition in our standard synthesis conditions of 10 $\mathrm{nm}$ spherical NPs (octylether solvent $\left(298^{\circ} \mathrm{C}\right)$ and oleic acid as surfactant) leads to 
spherical NPs with a monocrystalline structure and a $\mathrm{Fe}_{3-\mathrm{x}} \mathrm{O}_{4}$ homogeneous composition, only the size was slightly affected by the nature of iron stearate (about $9 \mathrm{~nm}$ with $\mathrm{FeSt}_{3}$ and $10 \mathrm{~nm}$ with $\mathrm{FeSt}_{2}$ )[22]. This was attributed to the fact that the decomposition kinetics of FeSt 2 at temperature below $298^{\circ} \mathrm{C}$ was higher than that of $\mathrm{FeSt}_{3}$ which decomposes on a larger temperature range up to $350^{\circ} \mathrm{C}$.

However, when we investigated then the synthesis process of $20 \mathrm{~nm}$ spheres (which are of great interest for magnetic hyperthermia) in a higher boiling point solvent, docosene $\left(367^{\circ} \mathrm{C}\right)$, NPs with sizes larger than $12 \mathrm{~nm}$ were only obtained when using $\mathrm{FeSt}_{3}$. In addition, a composition problem was often noticed with the formation of core-shell $\mathrm{Fe}_{1-\mathrm{x}} \mathrm{O} @ \mathrm{Fe}_{3-\mathrm{x}} \mathrm{O}_{4} \quad \mathrm{NPs}$ instead of NPs with a $\mathrm{Fe}_{3-\mathrm{x}} \mathrm{O}_{4}$ homogeneous composition[8]. Mean size higher than $10 \mathrm{~nm}$ needs organic solvents with high boiling point to ensure a sufficient growth of nuclei formed around $250^{\circ} \mathrm{C}[11,35]$. By contrast to $\mathrm{FeSt}_{2}, \mathrm{FeSt}_{3}$ provided enough monomer at temperature higher than $300^{\circ} \mathrm{C}$ to ensure the grain growth. Similarly, we always observed the formation of core-shell $\mathrm{Fe}_{1-\mathrm{x}} \mathrm{O} @ \mathrm{Fe}_{3-\mathrm{x}} \mathrm{O}_{4}$ nanocubes when decomposing iron oleate in presence of a mixture of oleic acid and sodium oleate in the high boiling point octadecene solvent.

These experiments and other reported results suggested the formation of wüstite $\mathrm{Fe}_{1-x} \mathrm{O}$ nuclei during such thermal decomposition process which oxidize more or less during the growth step[6,21,31]. When other iron precursor such as iron acetate is used as iron precursor, an intermediate formation of iron oleate in the synthesis mechanism is often reported. As iron oleate is mostly formed anyway, such study is interesting whatever the precursor. Before proposing mechanisms to explain such core-shell composition in the synthesis process, it is of great importance to prove the formation of $\mathrm{Fe}_{1-x} \mathrm{O}$ nuclei.

III.1 Thermal decomposition of iron stearates - Formation of $\mathrm{Fe}_{1-\mathrm{x}} \mathrm{O}$ nuclei 
In order to highlight the formation of $\mathrm{Fe}_{1-x} \mathrm{O}$ nuclei during the NPs synthesis, different temperature-dependent characterization techniques have been carried out on iron stearates.

TGA analysis. First, thermogravimetric analysis (TGA) was performed on $\mathrm{FeSt}_{2}$ and $\mathrm{FeSt}_{3}$. The weight loss curve with temperature is in agreement with previous published results[54-56] and especially those reported by Bronstein et al[35]. The TGA/DTG curves of the two precursors (Figure 1) evidenced four steps during the thermal treatment (area I-IV in Figure 1 and ref[22]). The first step (area I in Figure 1) below $150{ }^{\circ} \mathrm{C}$ is attributed to the loss of water molecules, the exothermic peak suggests the melting of the precursor in this area. The second event (area II in Figure 1) in the range $200-280^{\circ} \mathrm{C}$ corresponds to the first iron stearate decomposition step and has been attributed to the nucleation step during the NPs synthesis with the loss of some alkyl chains[22,35,55]. The third event (area III in Figure 1) occurs on a broader range of temperature for $\mathrm{FeSt}_{3}$ (from 290 to $380^{\circ} \mathrm{C}$ ) than $\mathrm{FeSt}_{2}$ (from 290 to $340^{\circ} \mathrm{C}$ ). This was ascribed to the decomposition of remaining more stable precursors contributing thus to the NPs growth. The last event (area IV in Figure 1) corresponds to the decomposition of organic products (burning) above $350{ }^{\circ} \mathrm{C}$ and is generally not observed in our synthesis conditions[22].
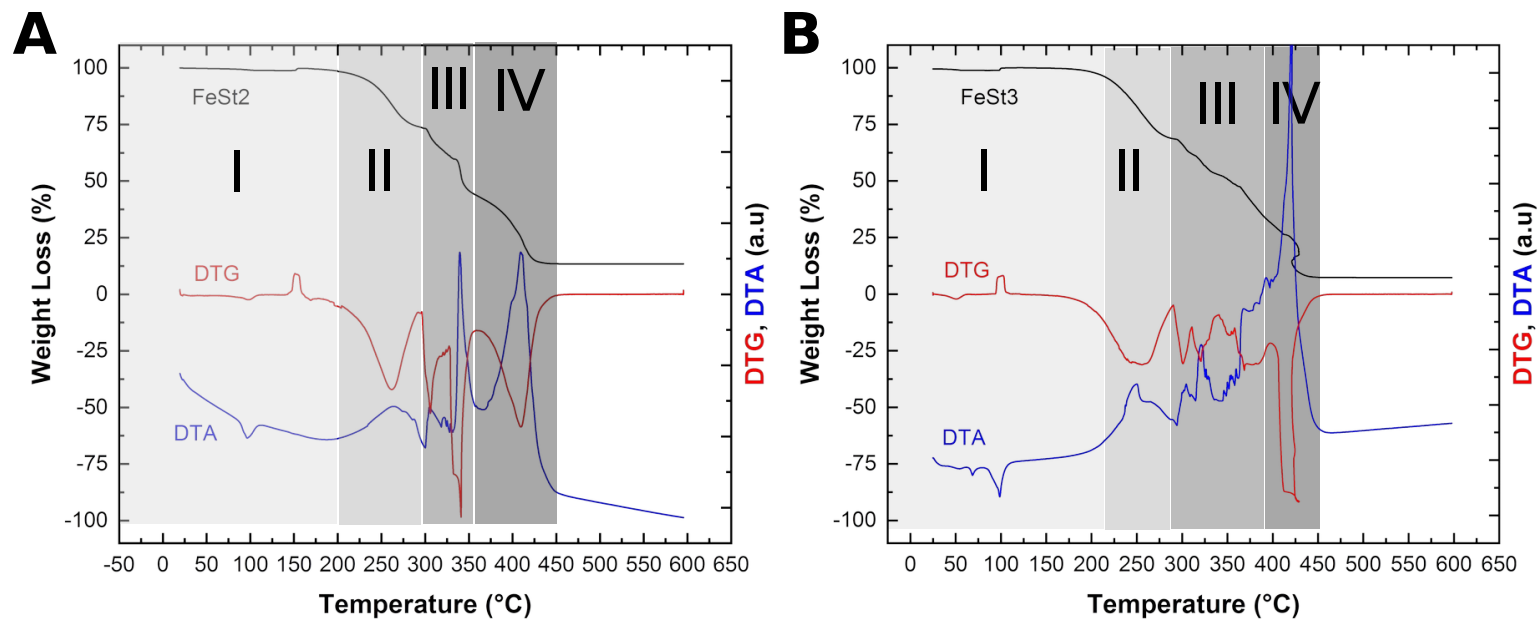

Figure 1. TGA (black line), DTG(red) and DTA(blue) curves of A) FeSt 2 and B) FeSt 3 . 
The identification of the series of events taking place during the thermal decomposition of the precursors with TGA/DTG curves was then studied by IR spectroscopy in temperature (Figures 2 and 3 ).

IR spectroscopy in temperature. IR spectra of both iron stearates at room temperature are presented in Figure 2 and their analysis is detailled in SI. The most intense alkyls bands are located in the $3000-2800 \mathrm{~cm}^{-1}$ high frequency region but also small bands are observed at $1465 \mathrm{~cm}^{-1}, 720 \mathrm{~cm}^{-1}$ and in the region between 1350 and $1150 \mathrm{~cm}^{-1}\left(\mathrm{CH}_{2}\right.$ wagging $\left(\omega \mathrm{CH}_{2}\right)$ bands). They confirm the presence of stearates with a lamellar structure.

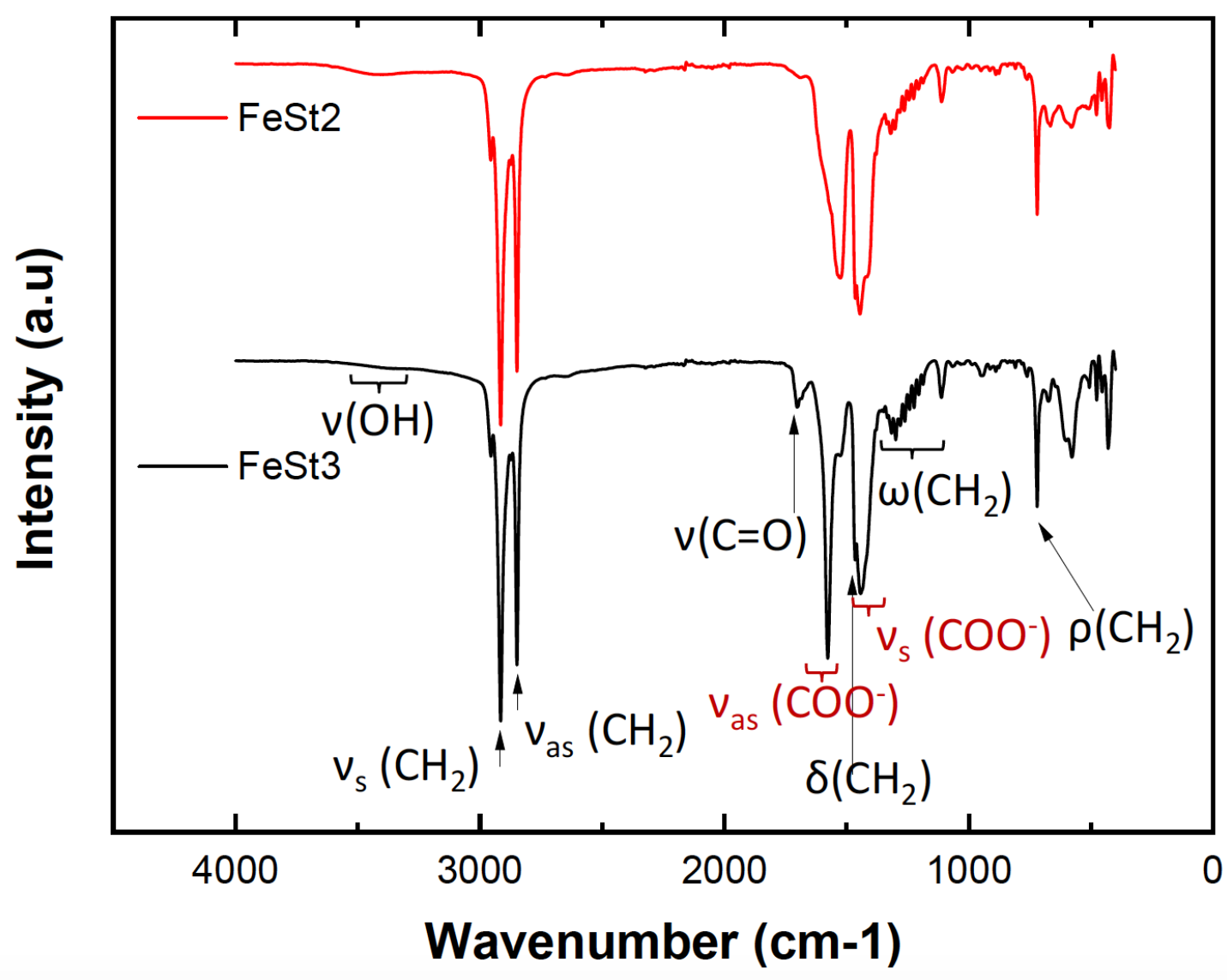

Figure 2. ATR IR spectra of FeSt 2 (red) and FeSt 3 (black) at room temperature

The bands in the region $1800-1400 \mathrm{~cm}^{-1}$ provide information on the carboxylate coordination with iron. Carboxylic acids generally present an asymmetric stretching 
singlet $\nu C=O$ around $1700 \mathrm{~cm}^{-1}[57,58]$. When coordinated to metal ions, this carbonyl band is splitted into a doublet with an antisymmetric $\mathrm{COO}^{-}$band $\left(\mathrm{v}_{\mathrm{as}} \mathrm{COO}\right)$ and the associated symmetric band $\left(\nu_{s} \mathrm{COO}\right)$. The carboxylate group can coordinate according to several modes on the metal center[59]. Beside the ionic coordination, three main coordinations are commonly observed : monodentate, bridging bidentate and chelate bidentate[60-63]. The analysis of these bands (detailed in SI) shows that both stearates $\mathrm{FeSt}_{2}$ and $\mathrm{FeSt}_{3}$ display carboxylates in bridging and chelate coordinations. From the carboxyl band intensities and position, one may advance that $\mathrm{FeSt}_{3}$ displays mainly a COO bridging coordination when $\mathrm{FeSt}_{2}$ displays mainly a chelate coordination[64].

IR spectra have been recorded as a function of the temperature under air (Figure 3). This technique should allow getting an insight of the mechanisms that are taking place during the thermal decomposition process.

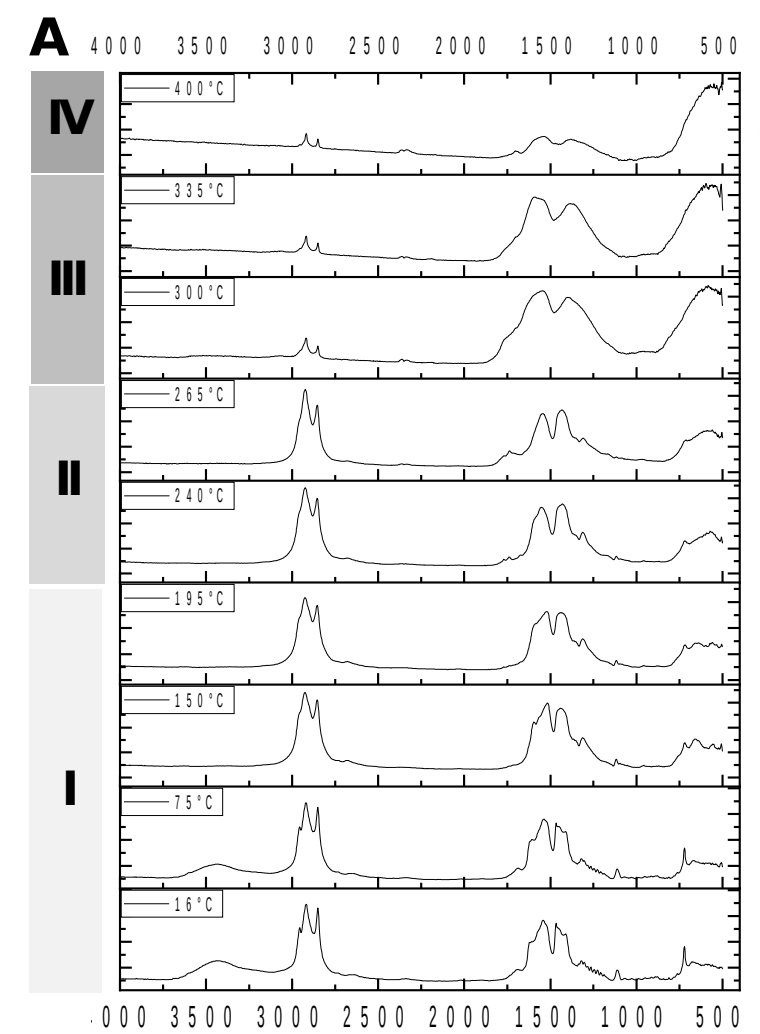

$\mathrm{FeSt}_{2}$ W avenumber $\left(\mathrm{cm}^{-1}\right)$

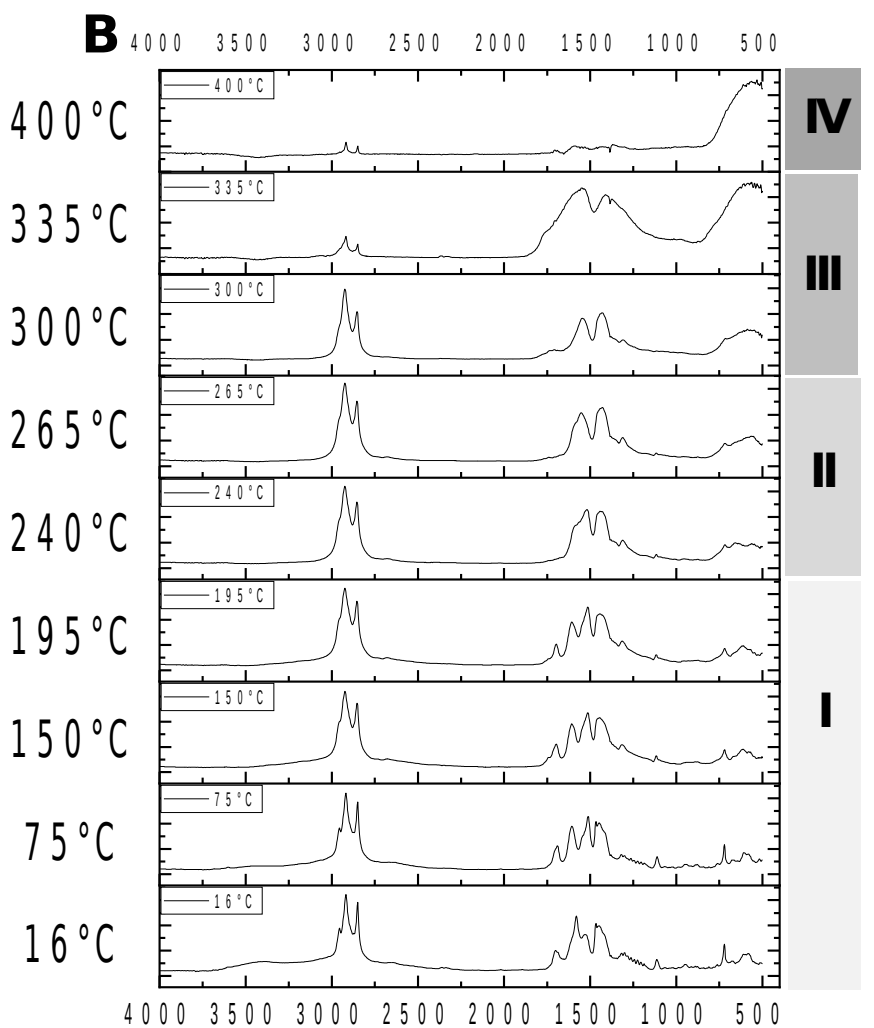

$\mathrm{FeSt}_{3}$ W avenumber $\left(\mathrm{cm}^{-1}\right)$

Figure 3. Evolution of the IR spectra with the temperature of A) $\mathrm{FeSt}_{2}$ and B) FeSt 
The four steps deduced from TGA curves (water molecule loss, nucleation step, growth step and decomposition of organic products) are also identified when following the IR bands evolution. In the first step (area I, Figure 3 ) the loss of the broad peak around $3500 \mathrm{~cm}^{-1}$ is consistent to the loss of water molecules present in the precursors. The loss of the wagging band progression above $75{ }^{\circ} \mathrm{C}$ agrees with the melting of the compounds in this temperature range. Finally, a structural reorganization of $\mathrm{FeSt}_{3}$ is observed through the evolution of the $\mathrm{COO}$ bands position with disappearance of the bridging coordination with water in favour of that of the chelate ones.

In the second step (area II, Figure 3), the appearance of the Fe-O broad band at 580 $\mathrm{cm}^{-1}$ is consistent with the fact that the nucleation step is in this temperature range. The temperature at which the Fe-O band appears is around $240{ }^{\circ} \mathrm{C}$ for $\mathrm{FeSt}_{2}$ and 265 ${ }^{\circ} \mathrm{C}$ for $\mathrm{FeSt}_{3}$ which is in quite good agreement with the position of the DTG peak in area II in Figure 1.

The third step shows the continuous increase of the intensity of the Fe-O band (area III in Figure 1) paired with the destabilization of the $\mathrm{COO}$ band, evidenced by the broadening of those bands. It corresponds to the further decomposition of precursor with higher stability contributing to the growth of the nuclei. Finally, in the last step, the intensity of organic bands (alkyl and COO bands) of the precursors decreases at high temperature (area IV in Figure 1), which matches with the burning of organic compounds generating $\mathrm{CO}_{2}$, among other products.

To corroborate the events observed with TGA and with IR spectroscopy in temperature, the intensities of IR bands of interest have been plotted as a function of temperature and compared to TGA curves (Figure 4) in oxidative experimental conditions. For FeSt ${ }_{2}$, selected bands are thus: $\mathrm{CH}_{2}$ (band at $\sim 2918 \mathrm{~cm}^{-1}$ ), $\mathrm{CO}_{2}$ (at $\left.\sim 2361 \mathrm{~cm}^{-1}\right)$, chelating carboxylate $v_{\mathrm{as}}\left(\mathrm{COO}^{-}\right)\left(\right.$at $\left.\sim 1545 \mathrm{~cm}^{-1}\right)$ and water $(\mathrm{OH}$ around 
$\sim 3465 \mathrm{~cm}^{-1}$ ) and for FeSt $3: \mathrm{CH}_{2}$ (band at $\sim 2918 \mathrm{~cm}^{-1}$ ), gaseous $\mathrm{CO}_{2}$ (at $\sim 2361 \mathrm{~cm}^{-1}$ ), bridging carboxylate $\nu_{\text {as }}(\mathrm{COO})$ (at $\sim 1580 \mathrm{~cm}^{-1}$ ) and water $\left(\mathrm{OH}\right.$ around $\sim 3415 \mathrm{~cm}^{-1}$ ). The areas I-III are clearly visible in this figure and the weight losses (dotted line in Figure 4) match quite well with the IR bands evolution.

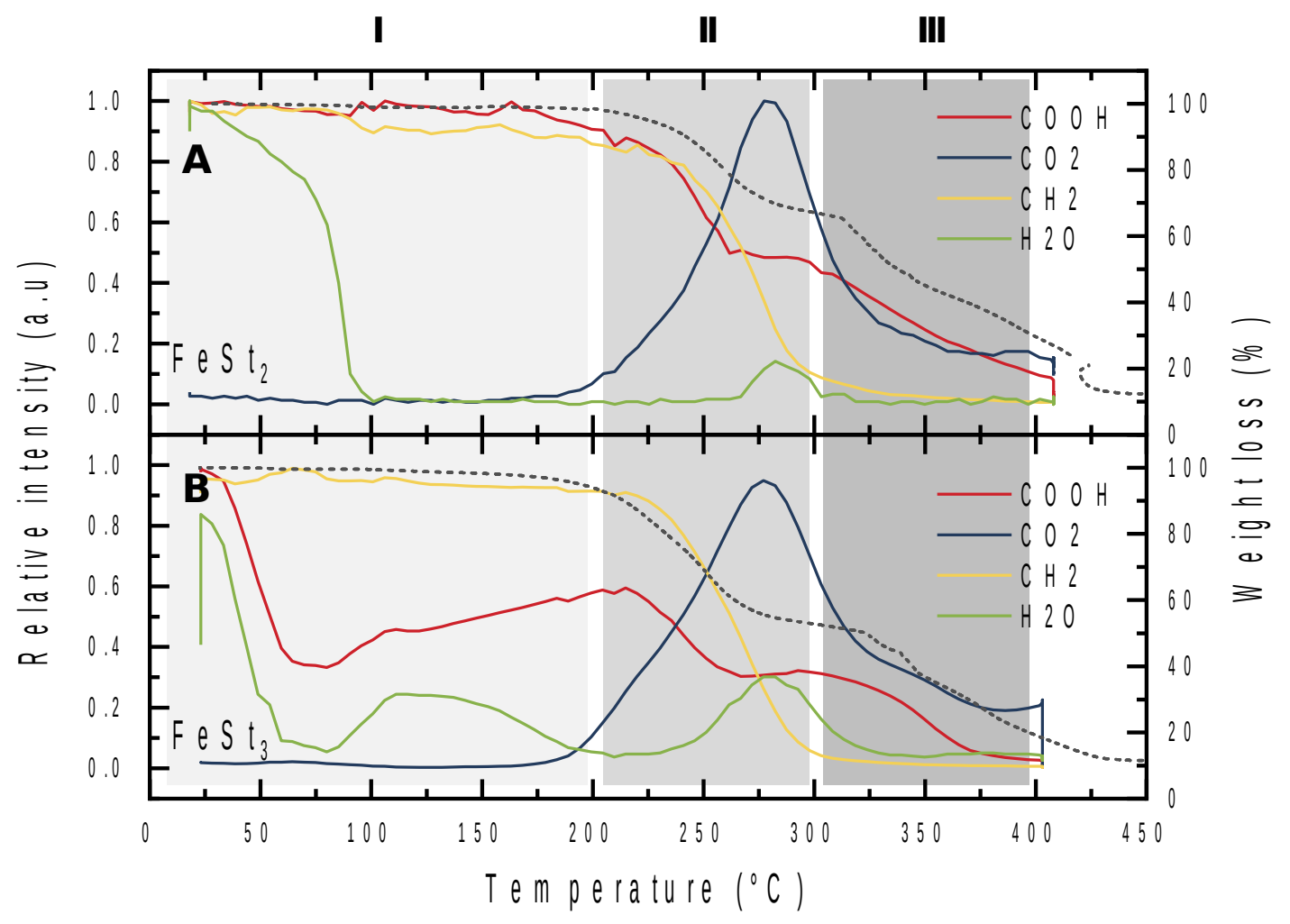

Figure 4. Evolution of IR bands of FeSt 2 A) and FeSt 3 B) as a function of heat treatment. $\left(\mathrm{COOH}=1545 \mathrm{~cm}^{-1} ; \mathrm{CO} 2=2361 \mathrm{~cm}^{-1} ; \mathrm{CH} 2=2918 \mathrm{~cm}^{-1} ; \mathrm{OH}=3415 \mathrm{~cm}^{-1}\right)$. TGA curves in doted lines.

For $\mathrm{FeSt}_{2}$, the evolution of IR bands of water with temperature confirmed a loss of water up to $100^{\circ} \mathrm{C}$ matching well with the loss of water molecules and one at higher temperature (areas II and III) attributed to water production during the decomposition of organic compounds. The IR peak of chelating carboxylate decreases after $190^{\circ} \mathrm{C}$ which may be attributed to stearate chains loss (in agreement with previous experiments and reported results[22,35,55]), then stabilizes and decreases again due to the decomposition step of organic compounds. 
The curves show more complex phenomena of dehydration and decomposition for $\mathrm{FeSt}_{3}$. Three water features are observed, the first at lower temperature $\left(50^{\circ} \mathrm{C}\right)$ in agreement with the observed weight loss from TGA curve, the second between 100 and $170^{\circ} \mathrm{C}$ and the last one at higher temperature attributed, as with $\mathrm{FeSt}_{2}$, to the decomposition of organic compounds.

The first water loss is associated with a change in the carboxylate coordination, which is related to the decrease of the intensity of the COO band in Figure 3 . Indeed, since we follow the evolution of the $1580 \mathrm{~cm}^{-1}$ (the $v_{\text {as }}\left(\mathrm{COO}^{-}\right)$linked to the bridging coordination) band, an intensity decrease is due to decarboxylation or coordination evolution. A close analysis of Figure 3 proves that the decrease is due to a change in the coordination. The evolution of the bridging coordination above $80^{\circ} \mathrm{C}$ and below $250^{\circ} \mathrm{C}$ may be linked to the water band evolution in this range of temperature and may be attributed to intermediate carboxylate coordination reorganization.

The decrease of the intensity of the $\mathrm{CH}_{2}$ bands is correlated with the weight loss observed in area II (Figure 4), confirming again that the weight loss in this area is associated to stearate chains loss. The formation of gaseous $\mathrm{CO}_{2}$ matches the loss of the stearate chain indicating a probable decomposition through decarboxylation which occurs in the same range of temperature for $\mathrm{FeSt}_{3}$ than for $\mathrm{FeSt}_{2}$. Therefore, the departure of stearates is observed together with the nucleation step.

Mössbauer spectrometry in temperature. We performed firstly Mössbauer spectrometry at 298 and $77 \mathrm{~K}$ to determine the iron oxidation degree in $\mathrm{FeSt}_{2}$ and $\mathrm{FeSt}_{3}$ precursors. The resulting spectra presented in Figure 5 (see relative transmission scale) are best resolved at $77 \mathrm{~K}$ compared to $298 \mathrm{~K}$. That may be attributed to the molecular structure of stearates, which is not so rigid at $300 \mathrm{~K}$ but becomes more rigid when cooling down (low value of Debye temperature). It is important to emphasize that the registration time was of 4-5 days at $300 \mathrm{~K}$ but less 
that one day at $77 \mathrm{~K}$ (using the same source and the same geometrical conditions). In addition, one observes clearly some rather symmetrical broadened quadrupolar features at $77 \mathrm{~K}$ while some asymmetry clearly occurs at $300 \mathrm{~K}$. Only the refined values of Mössbauer parameters at $77 \mathrm{~K}$ are summarized in Table 1.

Table 1. Mössbauer parameters at 77K (IS: isomer shift; QS: quadrupole splitting Area: proportions assuming that they are proportional to their respective absorption areas)

\begin{tabular}{|c|c|c|c|c|c|}
\hline \multicolumn{3}{|c|}{ FeSt $_{2}$} & \multicolumn{3}{c|}{ FeSt $_{3}$} \\
\hline IS $\left(\mathrm{mm} . \mathrm{s}^{-1}\right)$ & QS $\left(\mathrm{mm} . \mathrm{s}^{-1}\right)$ & Area \% & IS $\left(\mathrm{mm} . \mathrm{s}^{-1}\right)$ & QS $\left(\mathrm{mm} . \mathrm{s}^{-1}\right)$ & Area \% \\
\hline $0.50 \pm 0.01$ & $1.15 \pm 0.02$ & $42 \pm 2$ & $0.52 \pm 0.01$ & $0.76 \pm 0.02$ & $55 \pm 2$ \\
\hline $0.51 \pm 0.01$ & $0.70 \pm 0.02$ & $58 \pm 2$ & $0.53 \pm 0.01$ & $0.52 \pm 0.02$ & $45 \pm 2$ \\
\hline
\end{tabular}

The hyperfine structures at 77K, which are quite similar, can be well described by at least two quadrupole doublets characteristic of Fe (+III) cations in high spin state in all cases. The Mössbauer spectrum of $\mathrm{FeSt}_{2}$ at $300 \mathrm{~K}$ suggested the presence of $\mathrm{Fe}(+\mathrm{II})$ but its contribution is surprisingly not visible at $77 \mathrm{~K}$. The presence of $\mathrm{Fe}(+\mathrm{II})$ in $\mathrm{FeSt}_{2}$ would not be surprising as $\mathrm{FeSt}_{2}$ was synthesized using $\mathrm{FeCl}_{2} .4 \mathrm{H}_{2} \mathrm{O}$. Nevertheless, the present results indicate that all stearates are constituted of only $\mathrm{Fe}(+\mathrm{III})$ ions with mainly two different molecular environments. The presence of

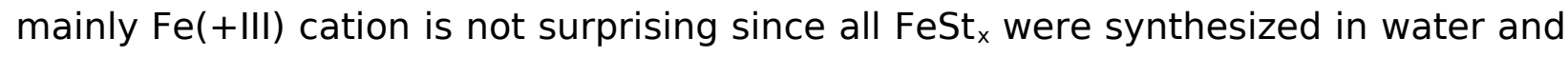
dried under air. In addition, oxidation of Fe (+II) could also occur during coprecipitation step or during the washing and drying processes $\left(65^{\circ} \mathrm{C}\right.$ overnight). 


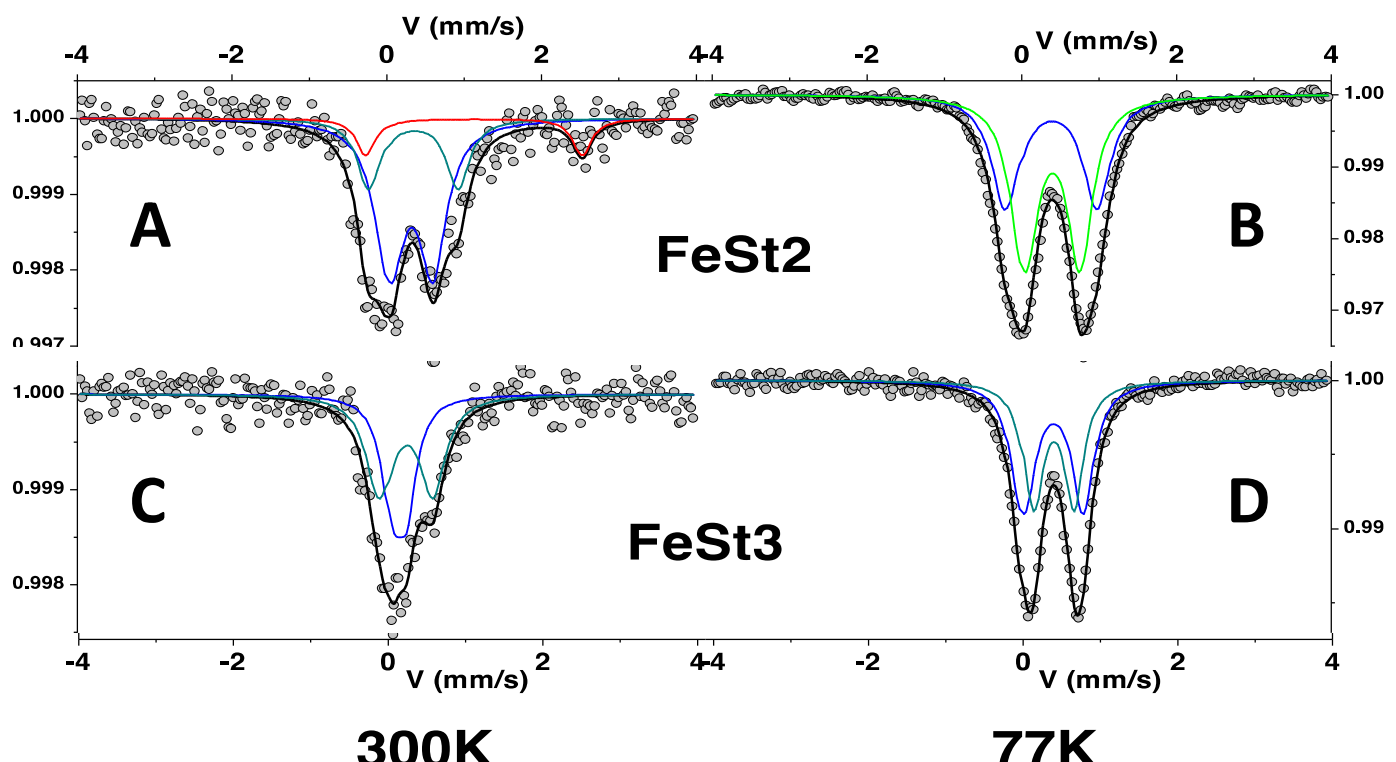

Figure 5. Mössbauer spectra of FeSt $2 A, B)$ and FeSt $3(C, D)$ at $300 K A, C)$ and $77 K(B, D)$.

To get a better insight on the oxidation degree of iron cations during the thermal decomposition of $\mathrm{FeSt}_{2}$ and $\mathrm{FeSt}_{3}$, Mössbauer spectra at different temperatures and heating times up to $140^{\circ} \mathrm{C}$ have been recorded using a cryofurnace where the powdered sample remained under vacuum. The refined values of the Mössbauer parameters are given in Table 2 .

Table 2. Evolution of isomer shifts (IS) of quadripolar shifts (QS) of FeSt 2 and FeSt with temperature. 


\begin{tabular}{|c|c|c|c|c|c|c|}
\hline \multirow[b]{2}{*}{$\mathrm{T}(\mathrm{K})$} & \multicolumn{3}{|c|}{$\mathrm{FeSt}_{2}$} & \multicolumn{3}{|c|}{$\mathrm{FeSt}_{3}$} \\
\hline & $\begin{array}{c}\text { IS }\left(\begin{array}{c}\mathrm{mm} \\
1 \\
1\end{array}\right) \\
\pm 0.01\end{array}$ & $\begin{array}{c}\text { QS } \\
\left(\mathrm{mm} . \mathrm{S}^{-1}\right) \\
\pm 0.02\end{array}$ & $\begin{array}{c}\text { Area } \\
\% \\
\pm 2\end{array}$ & 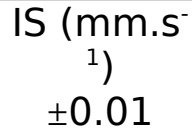 & $\begin{array}{c}\text { QS } \\
\left(\mathrm{mm} . \mathrm{S}^{-1}\right) \\
\pm 0.02\end{array}$ & $\begin{array}{c}\text { Area } \\
\% \\
\pm 2\end{array}$ \\
\hline \multirow{2}{*}{$77 \mathrm{~K}$} & 0.50 & 1.15 & 42 & 0.53 & 0.52 & 45 \\
\hline & 0.51 & 0.70 & 57 & 0.52 & 0.76 & 55 \\
\hline \multirow{2}{*}{ 77K under vacum } & 0.50 & 1.07 & 48 & 0.51 & 0.50 & 44 \\
\hline & 0.50 & 0.64 & 52 & 0.53 & 0.71 & 56 \\
\hline & \multicolumn{6}{|c|}{ Heat treatments } \\
\hline \multirow{2}{*}{$1 \mathrm{~h}$ at $50^{\circ} \mathrm{C}$} & 0.52 & 1.31 & 16 & 0.39 & 0.38 & 29 \\
\hline & 0.51 & 0.72 & 84 & 0.53 & 0.68 & 71 \\
\hline \multirow{2}{*}{$\begin{array}{c}\text { 1h at } 50^{\circ} \mathrm{C}+1 \mathrm{~h} \\
\text { at } 100^{\circ} \mathrm{C}\end{array}$} & 0.52 & 1.25 & 25 & 0.49 & 0.38 & 62 \\
\hline & 0.52 & 0.71 & 75 & 0.52 & 0.82 & 38 \\
\hline \multirow{3}{*}{$\begin{array}{c}\text { Ih at } 50^{\circ} \mathrm{C}+1 \mathrm{~h} \\
\text { at } 100^{\circ} \mathrm{C}+1 \mathrm{~h} \text { at } \\
140^{\circ} \mathrm{C}\end{array}$} & 0.58 & 1.35 & 22 & 0.24 & 0.34 & 13 \\
\hline & 0.52 & 0.69 & 69 & 0.53 & 0.69 & 87 \\
\hline & 1.25 & 3.11 & 9 & & & \\
\hline \multirow{3}{*}{$\begin{array}{c}\text { 1h at } 50^{\circ} \mathrm{C}+1 \mathrm{~h} \\
\text { at } 100^{\circ} \mathrm{C}+1 \mathrm{~h} \text { at } \\
140^{\circ} \mathrm{C}+15 \mathrm{~h}- \\
\mathrm{FeSt}_{2} \text { and } 20 \mathrm{~h}- \\
\mathrm{FeSt}_{3} \text { at } 140^{\circ} \mathrm{C}\end{array}$} & 0.74 & 1.06 & 11 & 0.28 & 0.34 & 20 \\
\hline & 0.49 & 0.77 & 75 & 0.52 & 0.77 & 56 \\
\hline & 1.24 & 3.01 & 14 & 1.27 & 2.78 & 24 \\
\hline
\end{tabular}

The Mössbauer spectra always evidence complexes with $\mathrm{Fe}(+\mathrm{III})$ in two different environments with a proportion close to 50:50 for stearates. A quadrupolar doublet (underlined in orange in table 2) is very similar for both stearates with IS 0.5 and QS 0.7: its proportion increases with temperature at the beginning and then fluctuates depending on the iron stearate. At the end of the whole heat treatment, its proportion is 56 and $75 \%$ for $\mathrm{FeSt}_{3}$ and $\mathrm{FeSt}_{2}$ respectively. We may consider that this heat-treatment under vacuum up to $140^{\circ} \mathrm{C}$ could correspond to a heattreatment up to $\sim 200-240^{\circ} \mathrm{C}$ under air. It should thus correspond quite to the thermal decomposition step up to the germination step.

For FeSt 2 , another quadrupolar doublet is identified with IS $\sim 0.5$ and QS $\sim 1.3 \mathrm{~mm} /$ S (brown line in Table 2). Below $100^{\circ} \mathrm{C}$, no major changes in QS/IS values are noticed; only the proportion is modified. Yet, after $1 \mathrm{~h}$ at $140^{\circ} \mathrm{C}$ under vacuum, we observe the appearance of another quadrupolar doublet (IS $=1.25$, QS $=3.11$ $\mathrm{mm} / \mathrm{s}$, grey line in Table 2), typical of HS Fe(+II). After $15 \mathrm{~h}$ heating at $140^{\circ} \mathrm{C}$ under vacuum, the proportion of iron II increases and a new doublet (IS $=0.74 ; \mathrm{QS}=1.06$ 
$\mathrm{mm} / \mathrm{s}$, yellow line) appears which is characteristic of a mixed valence in iron and corresponds certainly to $\mathrm{Fe}(+\mathrm{III})$ cations beginning to be reduced into $\mathrm{Fe}(+\mathrm{II})$.

For $\mathrm{FeSt}_{3}$, after heating at $100^{\circ} \mathrm{C}$, the same evolution as with $\mathrm{FeSt}_{2}$ is observed with the increase of the proportion of the first environment. Yet, once at $140^{\circ} \mathrm{C}$, the IS and QS decreases to 0.24 and $0.34 \mathrm{~mm} . \mathrm{s}^{-1}$ respectively, which would correspond to $\mathrm{Fe}(+\mathrm{III})$ in tetrahedral environment. This type of environment for iron is observed in the spinel phase. Based on modeling experiments[65], it was previously reported by us the possibility of such environment for iron when $\mathrm{FeSt}_{2}$ was heated[22], which was attributed to the intermediate formation of a Zundel complex. The modeling showed that the presence (or not) of this complex was related to the presence of water and would lead to a different pathway for the formation of oxide. It would prevent from the formation of $\mathrm{Fe}-\mathrm{O}$ unit but lead to $\mathrm{Fe}-\mathrm{OH}$ unit instead. Yet, the formation of such complex requires the presence of water, which should already be gone at this stage. The formation of $\mathrm{Fe}(+\mathrm{II})$ is observed after more than $20 \mathrm{~h}$ at $140^{\circ} \mathrm{C}$ which was longer than observed with $\mathrm{FeSt}_{2}$.

Mössbauer spectra as a function of temperature demonstrated that $\mathrm{Fe}(+\mathrm{III})$ cations are reduced during the thermal treatment under vacuum from $140^{\circ} \mathrm{C}$, which could be extrapolated to be about $250^{\circ} \mathrm{C}$ at atmospheric pressure. Thus, the reduction of $\mathrm{Fe}(+\mathrm{III})$ into $\mathrm{Fe}(+\mathrm{II})$ occurs in the range of temperature where nucleation is observed and is also attributed to stearate chains departure. The fact that $\mathrm{FeSt}_{2}$ underwent a reduction before $\mathrm{FeSt}_{3}$ agrees with TGA and IR analysis where the nucleation was observed earlier for FeSt $2\left(240{ }^{\circ} \mathrm{C}\right)$ than for FeSt $3\left(265^{\circ} \mathrm{C}\right)$.

Therefore, these experiments could confirm that the nucleation step occurs simultaneously with the reduction of $\mathrm{Fe}(+\mathrm{III})$. Moreover, the production of $\mathrm{CO}_{2}$ during the same step hints at a reduction mechanism induced by departure of carboxylate chain. This has been already observed during the synthesis of ketone with iron acting as a catalysist for the decarboxylation reaction[66-68]. 


\section{III.2 Influence of the nature of solvents and precursors on NPs composition}

When NPs with a mean size higher than $10 \mathrm{~nm}$ are targeted, the thermal decomposition must occur in an organic solvent with a boiling point higher than that of $\mathrm{OE}\left(298^{\circ} \mathrm{C}\right)$ in order to favor the grain growth step. However, in these conditions and for example in docosene $\left(\left(\mathrm{C}_{22} \mathrm{H}_{44}, 367^{\circ} \mathrm{C}\right)\right.$, a NPs core-shell composition is often obtained with a core of wustite and a shell of the spinel phase even if some experiments lead to the spinel composition. Considering the formation of wüstite nuclei, one may advance that the oxidation of the wüstite nuclei is affected by experimental conditions, especially when solvents with higher boiling point are used. We have thus investigated a possible effect of the nature of solvents.

In docosene, the alkene chain is over 20 carbons long. This implies that the solvent is solid at room temperature, which complicates the purification/washing steps of the NPs. We investigated at first the effect of the nature of solvent by performing experiments in squalane. Squalane, instead of an alkene solvent, also displays a high boiling point $\left(460^{\circ} \mathrm{C}\right)$ and has the advantage to be liquid at room temperature. However, when the synthesis temperature is above $350^{\circ} \mathrm{C}$, heterogeneous shaped- and sized- NPs have been formed. TGA experiments (Figure 1) showed that organic chains of iron stearates are completely degraded above this temperature[22,69] and this degradation during the synthesis should explain the uncontrolled growth and the observed size and shape dispersities. We thus performed the synthesis by imposing a reaction temperature of around $340^{\circ} \mathrm{C}$ (setting temperature at $360^{\circ} \mathrm{C}$ ) according to the TGA curve of in house $\mathrm{FeSt}_{3}$ (Figure 1). The problem with such high temperature (which does not correspond to the boiling temperature) is that it is quite hard to precisely control the reaction temperature and thus a temperature deviation (either 330 or $336^{\circ} \mathrm{C}$ ) was noticed between different experiments. Nevertheless, spherical NPs with mean size larger 
than $20 \mathrm{~nm}$ were successfully synthesized with squalane as observed in Figure 6 . As expected, the higher the reaction temperature, the higher was the size.
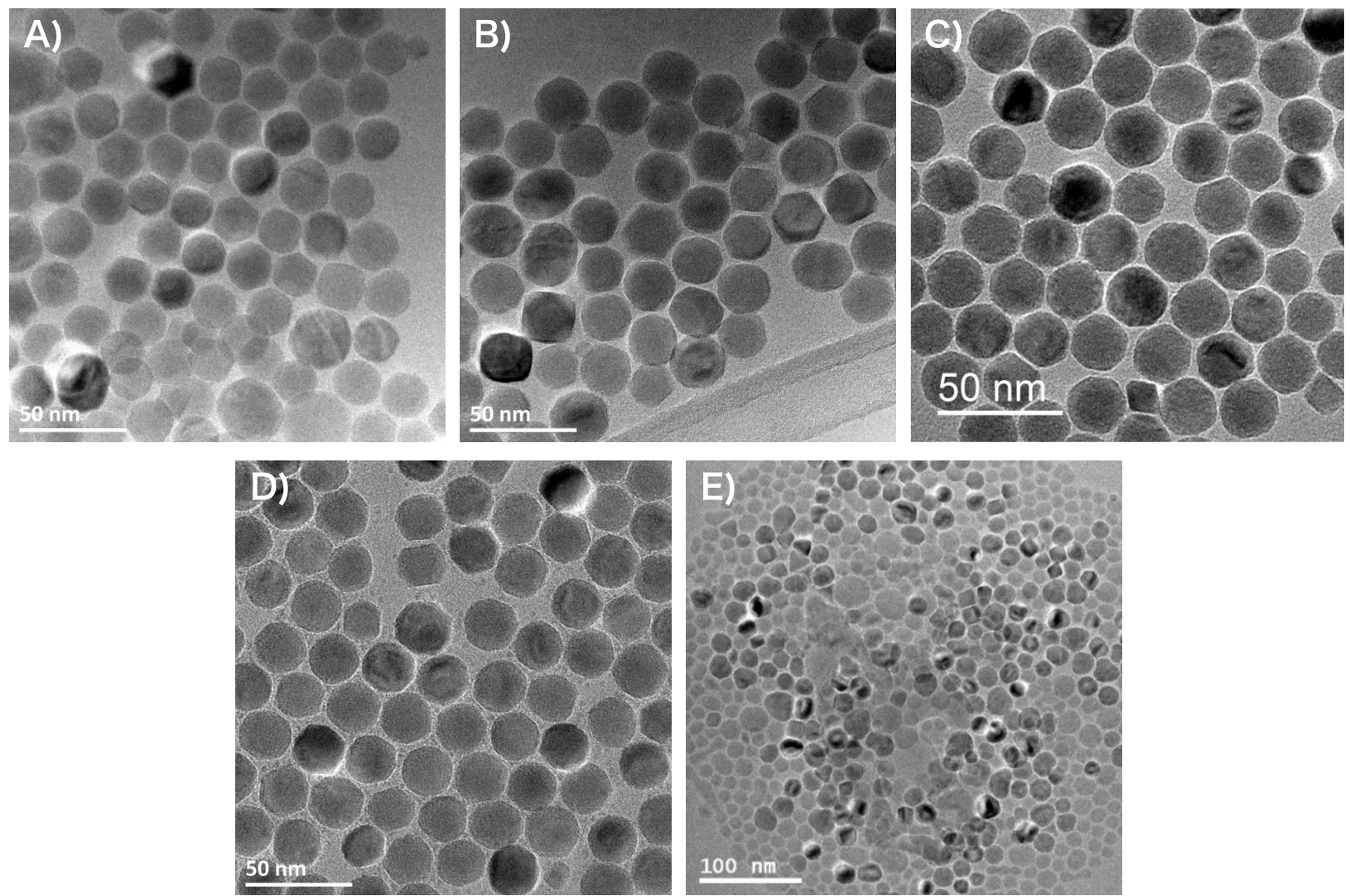

Figure 6. TEM images of IONPs synthesized in the $20 \mathrm{~nm}$ spheres conditions with squalane as solvent at $330^{\circ} \mathrm{C} \mathrm{A}$ ), $336{ }^{\circ} \mathrm{C} \mathrm{B}$ ); with squalane and small amount of DBE as solvent at 330 ${ }^{\circ} \mathrm{C} C$ ) and $335^{\circ} \mathrm{C} D$ ) and with octadecylether $\left.\mathrm{E}\right)$.

Table 3 - Structural parameters of the NPs synthesized in $20 \mathrm{~nm}$ spheres conditions (maghemite $\mathrm{\gamma}-\mathrm{Fe}_{2} \mathrm{O}_{3}(0.8346 \mathrm{~nm}$, JCPDS file 39-1346), wüstite (0.4326 nm, JCPDS file 01-89$687)$ and magnetite $\mathrm{Fe}_{3} \mathrm{O}_{4}(0.8396 \mathrm{~nm}$, JCPDS file 19-629))

\begin{tabular}{|c|c|c|c|c|}
\hline Solvent & $\begin{array}{l}\text { TEM size } \\
\text { (nm) }\end{array}$ & $\begin{array}{c}\text { Lattice } \\
\text { parameter }(\boldsymbol{A})\end{array}$ & $\begin{array}{l}\text { Spinel crystallite } \\
\text { size }(\mathrm{nm})\end{array}$ & $\begin{array}{l}\text { Compositi } \\
\text { on }\end{array}$ \\
\hline $\begin{array}{l}\text { Squalane } \\
\left(330^{\circ} \mathrm{C}\right)\end{array}$ & $21 \pm 1.3$ & $\begin{array}{l}4,240 \pm 0,001 \\
8,369 \pm 0,001\end{array}$ & ND & $\begin{array}{c}\mathrm{Fe}_{1-\mathrm{x}} \mathrm{O} @ \mathrm{Fe}_{3-} \\
\times \mathrm{O}_{4}\end{array}$ \\
\hline $\begin{array}{c}\text { Squalane } \\
\left(336^{\circ} \mathrm{C}\right)\end{array}$ & $24.5 \pm 2.0$ & $8,386 \pm 0,001$ & $14 \pm 1$ & $\mathrm{Fe}_{3-x} \mathrm{O}_{4}$ \\
\hline $\begin{array}{c}\text { Squalane } \\
+ \text { DBE } \\
\left(330^{\circ} \mathrm{C}\right)\end{array}$ & $17,9 \pm 1,4$ & ND & ND & $\mathrm{Fe}_{3-\mathrm{x}} \mathrm{O}_{4}$ \\
\hline $\begin{array}{c}\text { Squalane } \\
+ \text { DBE } \\
\left(335^{\circ} \mathrm{C}\right)\end{array}$ & $22.2 \pm 1.8$ & $8.391 \pm 1$ & $13 \pm 1$ & $\mathrm{Fe}_{3-x} \mathrm{O}_{4}$ \\
\hline
\end{tabular}


Yet, we observed that depending on the effective reacting temperature, some variations in the composition from a spinel phase to core-shell NPs with a wüstite core can occur (Table 3). Several experiments with strong control of heating conditions have confirmed a correlation between the reaction temperature and the NPs composition. If the temperature is below $335^{\circ} \mathrm{C}$, the observed composition from XRD pattern is a core shell $\mathrm{Fe}_{1-x} \mathrm{O} @ \mathrm{Fe}_{3-x} \mathrm{O}_{4}$ one (Figure $\mathrm{S} 1$ and Table 3 ) but if it is in the range $335-345^{\circ} \mathrm{C}$, a homogeneous $\mathrm{Fe}_{3-\mathrm{x}} \mathrm{O}_{4}$ phase is formed.

Since we faced issues controlling the reflux temperature with squalane as the only solvent, we proposed to mix it with a solvent displaying a lower boiling point. As the reflux temperature is not easy to predict in these solvent mixtures, the setting temperature was always fixed to $360^{\circ} \mathrm{C}$ for these experiments. At first, we mixed squalane with different amounts of dioctylether $\left(\mathrm{OE}, \mathrm{bp}=287^{\circ} \mathrm{C}\right)$. The different ratios conducted to a tuning of the reaction temperature and the results are given in Table 4. TEM images of some as-synthesized NPs are given in Figure S2 and the mean diameters are reported in Table 4 . When FeSt 2 is used as precursor, an increase of the size is observed, but the sizes stay lower than $15 \mathrm{~nm}$, as expected. It confirms again that most $\mathrm{FeSt}_{2}$ decomposed below $300^{\circ} \mathrm{C}$ and that only few precursors are available for the growth step[22].

With $\mathrm{FeSt}_{3}$, the temperature strongly influenced the NPs diameter with an increase of the mean size with the increase in the reflux temperature (Table 4 and Figures S2\&S3), ranging from about $6 \mathrm{~nm}$ for $\mathrm{OE}$ to $18 \mathrm{~nm}$ when a mixture SQ:OE 15:5 is used a solvent (Figure S3). However, one may notice that in pure squalane, a reaction temperature close $\left(336^{\circ} \mathrm{C}\right)$ or lower $\left(330^{\circ} \mathrm{C}\right)$ than that of the mixture $15: 5\left(338^{\circ} \mathrm{C}\right)$ leads to NPs with higher mean sizes. The mean size difference is more evident with the $10: 10$ mixture, which led to $11.7 \mathrm{~nm}$ NPs when $21 \mathrm{~nm}$ sized NPs were obtained at $330^{\circ} \mathrm{C}$ in pure squalane. Moreover, the temperature difference betwen ratios $10: 10$ and $15: 5$ is only $6^{\circ} \mathrm{C}$ and the size increases from 11.7 to 18.1 
$\mathrm{nm}$ respectively. The comparison between experiments in squalane and in $\mathrm{SQ}: \mathrm{OE}$ showed that there is an influence of the solvents's nature on the decomposition/synthesis mechanism. SQ appears to favour the grain growth when OE would favour the nucleation step. Such impact of OE on the synthesis mechanism has already been noticed in previous studies[11]: OE would interact with iron precursor and lower its decomposition temperature. It induces thus the generation of high amounts of monomers during the nucleation step leading to a high number of small nuclei and few precursors are still available for decomposition at higher temperature, therefore limiting the growth step. By contrast, SQ would preserve the precursor which decomposes mainly at high temperature. Therefore, in that last case, the nucleation step generates low amounts of nuclei and more monomers are available for the growth step. As the nucleation step is reported to occur when the iron stearate/iron oleate losses a carboxylate chain[22,35,39,39], OE should activate/favour this loss of the carboxylate chains by interacting with iron stearates and perhaps replacing these chains (kind of ligand exchange).

Table 4. Synthesis conditions with different SQ/OE solvent ratios and mean diameter of as-synthesized NPs. The amount of precursor and ligand is kept constant (2.2 mmol of iron stearate for $4.4 \mathrm{mmol}$ of oleic acid), only the solvent ratio is modified, which tunes the reaction temperature accordingly. The setting temperature applied by the heating mantle is fixed at $360^{\circ} \mathrm{C}$ for all experiments.

\begin{tabular}{|c|c|c|c|}
\hline Precursor & $\begin{array}{c}\text { SQ:OE } \\
(\mathbf{m L})\end{array}$ & $\begin{array}{c}\text { Reaction T } \\
\left({ }^{\circ} \mathbf{C}\right)\end{array}$ & $\begin{array}{c}\text { Diameter } \\
(\mathbf{n m})\end{array}$ \\
\hline \multirow{4}{*}{ FeSt $_{2}$} & $20: 0$ & 336 & $15 \pm 1$ \\
\cline { 2 - 4 } & $15: 5$ & 338 & $13 \pm 2$ \\
\cline { 2 - 4 } & $10: 10$ & 332 & $12 \pm 1$ \\
\cline { 2 - 4 } & $5: 15$ & 316 & $9 . \pm 1$ \\
\cline { 2 - 4 } & $0: 20$ & 301 & $11 \pm 1$ \\
\hline \multirow{4}{*}{ FeSt $_{3}$} & $20: 0$ & 336 & $25 \pm 2$ \\
\cline { 2 - 4 } & $20: 0$ & 330 & $21 \pm 2$ \\
\cline { 2 - 4 } & $15: 5$ & 338 & $18 \pm 3$ \\
\cline { 2 - 4 } & $10: 10$ & 332 & $12 \pm 2$ \\
\cline { 2 - 4 } & $5: 15$ & 316 & $8 \pm 1$ \\
\cline { 2 - 4 } & $0: 20$ & 301 & $6 \pm 1$ \\
\hline
\end{tabular}


The NPs synthesized in the conditions of SQ:OE 15:5, which display the highest mean diameter were further analysed by XRD (Figure S4). Profile matching of the XRD pattern of $18 \mathrm{~nm}$ NPs performed using FullProf Sotftware showed that NPs are composed of two phases: the spinel (either magnetite or maghemite) and the wüstite ones.

Synthesis of NPs in OE, which occurs at lower temperature $\left(298^{\circ} \mathrm{C}\right)$, led to $10 \mathrm{~nm}$ NPs with a homogeneous composition. Experiments in mixture of SQ and OE conducted to core-shell NPs and evidenced an impact of OE which presence conducts to smaller NPs and this even at higher temperature than pure SQ (Table 4). However, we had expected an impact of OE on the composition of NPs as Pellegrino's group[3,7] succeeded in synthesizing nanocubes with high size with a homogeneous spinel composition by using adapted mixture of SQ and dibenzylether (DBE) as solvents. Nevertheless, DBE was reported to decompose, during the thermal decomposition process and the decomposition products, especially benzaldehyde, to drive the cubic shape. Indeed such benzyl ether decomposed at high temperature mainly into toluene and benzaldehyde[7,70] and at temperature around $300^{\circ} \mathrm{C}[71]$. The higher the amount of squalane, the higher the reaction temperature was and the NPs composition was always a homogeneous one. We reproduced similar synthesis conditions and since a larger fraction of DBE induced the shape of the NPs to be modified (nanocube and octopod shapes), the optimal selected condition was the decomposition of $\mathrm{FeSt}_{3}$ in squalane with a small amount of DBE (2.5\% of the total synthesis volume). Given that the aim is to use these NPs in vivo, the choice of SQ is pertinent as it is highly biocompatible[72] and the use of very small amount DBE is recommended since the use or production of toxic species during the NPs synthesis must be restricted/avoided. 
To further investigate the role of the solvent nature on the NPs size and especially that of ether solvents, the synthesis conditions of $20 \mathrm{~nm}$ NPs was then performed in an ether similar to octylether $\left.\left(\mathrm{C}_{8} \mathrm{H}_{17}\right)_{2} \mathrm{O}\right)$ but with a higher boiling point, octadecylether $\left(\left(\mathrm{C}_{18} \mathrm{H}_{37}\right)_{2} \mathrm{O}, \mathrm{B}_{\mathrm{p}} 548^{\circ} \mathrm{C}\right)$, to ensure the growth step up to $20 \mathrm{~nm}$. The thermal decomposition led to heterogeneous round-shaped NPs (Figure 6E) with a mean diameter of $13.1 \pm 1.9 \mathrm{~nm}$ when excluding some few larger NPs with a mean diameter around $20 \mathrm{~nm}$. However, it was noticed that the temperature in the media did not exceed $320^{\circ} \mathrm{C}$ even if the setting temperature was higher. The mean size obtained at $320^{\circ} \mathrm{C}$ is in agreement with the size obtained in previous experiment at such synthesis temperature (eicosene) but the less homogeneous NPs shapes (Figure 6E) and sizes suggested interactions between reactants (solvent, ligand, precursor) and a lower control of the growth process. Such slightly lower temperature despite the higher setpoint may perhaps be attributed to a pyrolysis of octadecylether as some ethers have been reported to decompose at high temperature of around $300^{\circ} \mathrm{C}[73]$. Another hypothesis is that ether solvents interact with reactants and/or products which affects the synthesis reactions. The use of ether solvents appears therefore to be complex at high temperature $\left(>300^{\circ} \mathrm{C}\right)$ due to their possible decomposition/pyrolysis or reactivity with reactants.

Concerning the composition of NPs with mean size of about $20 \mathrm{~nm}$, when coreshell NPs were obtained in squalane and a mixture of squalane and octyl ether, the introduction of small amounts of DBE in squalane resulted in the synthesis of about $20 \mathrm{~nm}$ spherical NPs with a homogeneous $\mathrm{Fe}_{3-\mathrm{x}} \mathrm{O}_{4}$ spinel composition. The size could then be tuned by playing on the growth temperature (by staying below $350^{\circ} \mathrm{C}$ ) allowing the synthesis of NPs with a mean size of $18 \mathrm{~nm}$ (named NS18) at $330^{\circ} \mathrm{C}$ and $22 \mathrm{~nm}$ (named NS22) at $335^{\circ} \mathrm{C}$ (Figure 6.C\&D, S1.A\&B and Table 3). The refined XRD pattern of NS22 in Figure S1.B is characteristic of both NS18 and NS22 samples and displays the X-ray peaks of a spinel structure. Rietveld refinements led to a 
lattice parameter of $8.391 \pm 1 \AA$, suggesting a composition very close to that of the stoichiometric magnetite $\mathrm{Fe}_{3} \mathrm{O}_{4}$ phase $(0.8396 \mathrm{~nm}$, JCPDS file 19-629). However, a crystallite size of $13 \pm 1 \mathrm{~nm}$ was determined from XRD refinement, which is lower than the $22 \mathrm{~nm}$ size measured from TEM images. As the HRTEM images evidenced no amorphous part in these NPs, such size discrepancy is attributed to the presence of defects[8,11]. Such a discrepancy was earlier observed with core-shell nanocubes further oxidized and was demonstrated to be due to the presence of defects formed during the oxidation of $\mathrm{Fe}_{1-\mathrm{x}} \mathrm{O}$ in the magnetite phase[8,11]. Indeed our previous studies on core-shell $\mathrm{Fe}_{1-\mathrm{x}} \mathrm{O} @ \mathrm{Fe}_{3-\mathrm{x}} \mathrm{O}_{4}$ nanocubes[8,21] and the work of Bergstrom et al[31] have shown that the post-oxidation of $\mathrm{Fe}_{1-\mathrm{x}} \mathrm{O}$ induced the formation of lattice dislocations and/or antiphase boundaries in NPs. FFT analysis of HRTEM images confirmed the presence of defects in these NPs. That would explain the smaller structural coherence length compared to the TEM size as well as a lattice parameter close to that of magnetite. Strains/defects induced by the oxidation of wustite lead to a surestimated lattice parameter[21]. A better evaluation of the exact composition may be obtained when considering the Fe-O bands in IR spectra as IR spectroscopy allows the discrimination of magnetite (one band at $580 \mathrm{~cm}-1$ ) and maghemite phases (broad bands between 800 and $400 \mathrm{~cm}^{-1}$ )[11]. The consideration of the Fe-O bands in the IR spectra showed a main broad band centered at $610 \mathrm{~cm}^{-1}$ with a shoulder at lower wavenumbers (Figure S5), indicating that the magnetite phase is in fact slightly oxidized[11,74]. That demonstrated again that a combination of different characterization techniques is necessary to really determine the composition of the spinel phases[75]. In addition, as the spinel composition resulted from an oxidation of the wustite phase, one may advance that the growth rate was higher than the oxidation one and that the oxidation rate was never high enough to avoid the core-shell composition. 
At this stage, we can see that solvents play important role in NPs size and composition. We notice that an impact of the nature of solvent on the NPs shape and in particular on its iron chelation ability has already been reported[76,77]. Octyl ether added to a solvent mixture does not favor the formation of NPs with a homogeneous spinel composition but does affect the NPs size. OE favours the nucleation step by interacting with the iron stearate which decomposes highly at lower temperature. Considering the formation of $\mathrm{Fe}_{1-\mathrm{x}} \mathrm{O}$ nuclei and observing that experiments in OE (low boiling point solvent) conducted to fully oxidized spinel iron oxide NPs (e.g. without a $\mathrm{Fe}_{1-\mathrm{x}} \mathrm{O}$ core) when high boiling point solvent conducts to core-shell NPs, one may advance that:

- octyl ether with a low boiling temperature favors the nucleation step and leads to large number of nuclei and at this small size, the oxidation should be fast

- In high boiling point solvents, the reaction temperature is higher and the growth rate will be faster than the oxidation rate of the wüstite phase.

- By contrast, very small amounts of DBE in squalane (high boiling point solvent) conducts to a homogeneous spinel composition.

One question arises: what is the role of DBE in the observed higher oxidation rate by comparison with those with alkane, alkene and mixtures of SQ and OE solvents? The hypothesis would be that DBE helps to enhance the oxidation rate during the growth step.

Therefore, to identify what the reactants or mechanisms preventing nuclei from oxidation are, syntheses at low reaction temperature have been investigated.

\section{III.3 Influence of reactants on NPs composition}

To highlight the possible roles of the reactants on the oxidation kinetics, the decomposition of $\mathrm{FeSt}_{2}$ using the standard $10 \mathrm{~nm}$ spheres protocol was performed with oleic acid (OA) as surfactant and $\mathrm{OE}$ as solvent in several experimental conditions but always with heating rate of $5{ }^{\circ} \mathrm{C} / \mathrm{min}$ and heated to reflux for $2 \mathrm{~h}$ 
under air. Two experiments were conducted 1) with or 2) without the octylether (OE) solvent (in those last conditions, the surfactant can act as a solvent). Then a third experiment has also been realized where both ligand and solvent were removed and sole $\mathrm{FeSt}_{2}$ was decomposed. Figures 7.A-C and S6 display the TEM images and XRD pattern of as synthesized NPs and Table 5A, the structural parameters.

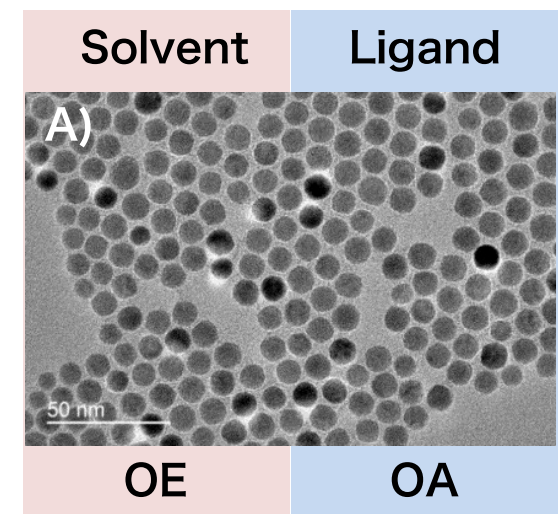

$\mathrm{Fe}_{3-\mathrm{x}} \mathrm{O}_{4}$

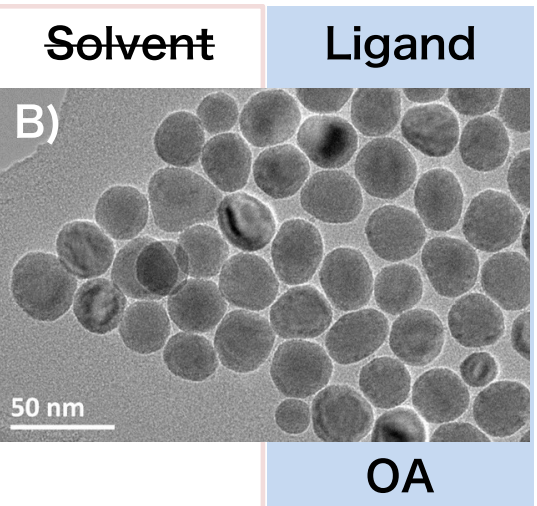

$\mathrm{Fe}_{1-\mathrm{x}} \mathrm{O} @ \mathrm{Fe}_{3-\mathrm{x}} \mathrm{O}_{4}$

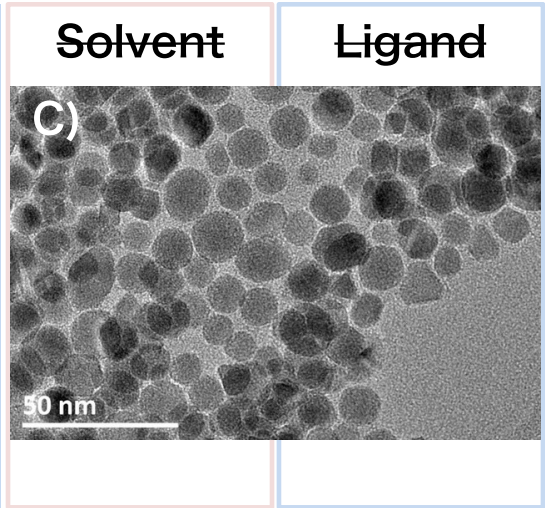

$\mathrm{Fe}_{3-\mathrm{x}} \mathrm{O}_{4}$

Figure 7: TEM images of NPS synthesized with solvent (octyl ether (OE)) and surfactant (oleic acid (OA)) A), without solvent and with ligand (OA) B), without solvent and ligand C).

Table 5. Structural parameters of the NPs synthesized in the $10 \mathrm{~nm}$ spheres conditions (maghemite $\mathrm{y}-\mathrm{Fe}_{2} \mathrm{O}_{3}(0.8346 \mathrm{~nm}$, JCPDS file $39-1346)$, wüstite $(0.4326$ nm, JCPDS file 01-89-687) and magnetite $\mathrm{Fe}_{3} \mathrm{O}_{4}(0.8396 \mathrm{~nm}$, JCPDS file 19-629))

$\begin{array}{ccccc}\text { Parameter } & \begin{array}{c}\text { TEM size } \\ (\mathbf{n m})\end{array} & \begin{array}{c}\text { Lattice } \\ \text { parameter }(\boldsymbol{A})\end{array} & \begin{array}{c}\text { Spinel crystallite } \\ \text { size }(\mathbf{n m})\end{array} & \begin{array}{c}\text { Composi } \\ \text { tion }\end{array} \\ \begin{array}{c}\text { Solvent }+ \\ \text { ligand }\end{array} & 10 \pm 1 & 8,379 \pm 0.001 & 10 \pm 1 & \mathrm{Fe}_{3-\mathrm{x}} \mathrm{O}_{4} \\ \text { Ligand } & 27 \pm 4 & 4.262 \pm 0.001 & 7 \pm 1 & \mathrm{Fe}_{1-\mathrm{x}} \mathrm{O} \\ \boldsymbol{\varnothing} & 12 \pm 2 & 8.386 \pm 0.001 & 8 \pm 1 & \mathrm{Fe}_{3-\mathrm{x}} \mathrm{O}_{4}\end{array}$


In the presence of solvent and ligand, $10.3 \pm 0.8 \mathrm{~nm} \mathrm{Fe} \mathrm{z}_{3-\mathrm{x}} \mathrm{O}_{4}$ spherical NPs were obtained as expected with the standard protocol[11]. The good agreement between the TEM diameter and the cristallite size determined from XRD pattern confirmed the formation of a monocrystal as proved by HRTEM and already published characterizations[11]. When the solvent is removed, and sole OA is introduced (as solvent and surfactant), NPs with a TEM mean size of $27.5 \pm 3.8 \mathrm{~nm}$, an ovoid shape and a $\mathrm{Fe}_{1-\mathrm{x}} \mathrm{O}$ composition were obtained. When sole $\mathrm{FeSt}_{2}$ is decomposed, slightly oxidized magnetite NPs, with a mean size of $11.9 \pm 2.3 \mathrm{~nm}$ and a rather spherical shape, are obtained but the discrepancy between the crystallite determined from XRD patterns and TEM size suggested a spinel phase resulting from the oxidation of wüstite.

One may notice that when only oleic acid is present and acts as solvent and ligand, the wüstite $\mathrm{Fe}_{1-x} \mathrm{O}$ phase is mainly obtained when an oxidized spinel phase is observed without solvent and ligand. These results suggest a strong role of the OA surfactant in the preservation/protection of the $\mathrm{Fe}_{1-\mathrm{x}} \mathrm{O}$ composition. As already evidenced by Lisiecky et al[78] with cobalt NPs protected from oxidation thanks to their docanoic acid coating, oleic acid should form a dense monolayer at the surface of NPs, preventing $\mathrm{Fe}_{1-\mathrm{x}} \mathrm{O}$ nuclei from oxidation.

The higher NPs size without OE by comparison with that of experiments in presence of octyl ether confirmed again that OE favors the nucleation by favoring the decomposition rate of the precursor at the nucleation temperature. It replaces/interacts with stearate chains in iron stearate, therefore affecting their thermal stability. However, with octyl ether, a homogeneous spinel composition is obtained without defects supporting an oxidation rate slightly higher or similar to that of the growth step. When only iron stearate is decomposed, the spinel composition of NPs with defects suggests that the oxidation rate was slightly lower than the growth rate. Thus, one may advance that octylether should also slightly 
contribute to the oxidation rate. In addition, the decomposition of iron stearate alone shows that the nuclei can be oxidized in this condition which is not the case when oleic acid is added.

Our hypothesis is that when wüstite nuclei are formed, they are coated with an oleic acid/stearate chains monolayer. This monolayer is very dense and impermeable to oxygen when iron stearate is decomposed in presence of oleic acid and, to contrast with when octyl ether is added, it should interact with this monolayer, exchange with oleic acid or stearate chains, affect the monolayer density/impermeability and thus enhance the oxidation rate. The composition corresponding to the spinel one, when only iron stearate is decomposed, may be ascribed to the fact that the stearate monolayer without oleic acid is not dense/impermeable enough to prevent nuclei from oxidation.

These experiments at low temperature show that oleic acid prevents NPs from oxidation and that OE affects the oxidation rate by acting on the impermeability of the monolayer. All these experiments, our previous works[8,21,37] and recent published works[37,79] confirmed the formation of $\mathrm{Fe}_{1-\mathrm{x}} \mathrm{O}$ nuclei.

\section{III.4 Discussion}

The synthesis of spinel iron oxide NPs with mean size around $20 \mathrm{~nm}$ by thermal decomposition requires the use of an organic solvent with a high boiling point to ensure a sufficient growth of nuclei formed around $250^{\circ} \mathrm{C}$. However, with solvents with high boiling points such as alkene, alkane or a mixture of squalane and octyl ether, a core-shell wustite-spinel composition is often obtained instead of the expected $\mathrm{Fe}_{3-x} \mathrm{O}_{4}$ ones.

It was often suggested that the thermal decomposition method led to nuclei with a wüstite composition but even if the formation of $\mathrm{Fe}_{1-\mathrm{x}} \mathrm{O}$ nuclei was suggested in earlier works, it has, to the best of our knowledge, not been demonstrated. The investigation of the thermal decomposition of iron stearates by TGA, IR and 
Mössbauer spectroscopies as a function of temperature have evidenced that stearate chains are lost during the nucleation step and that $\mathrm{Fe}(+\mathrm{III})$ is reduced during this stage.

The experiments where either $\mathrm{OE}$ and/or solvent are removed in the thermal decomposition of iron stearate confirmed yet the formation of wüstite nuclei. In addition, these experiments at low temperature aiming at the decomposition of iron stearate alone, then conducted in presence of oleic acid and finally in presence of oleic acid and OE (Figure 8 ) showed that the presence of oleic acid prevents $\mathrm{Fe}_{1-x} \mathrm{O}$ nuclei from oxidation. The addition of OE conducts to a smaller NPs size, a spinel composition and no defects. OE has already been reported to favour the nucleation step by affecting the iron stearate's thermal stability: it may interact with carboxylate chains or exchange with them. OE enhances the decomposition of iron stearate by affecting its thermal stability and thus favors the nucleation of large amounts of small nuclei. These small nuclei are easily oxidized during the synthesis and the oxidation kinetics are similar or higher than the growth ones. In addition, the experiments here suggested that OE also slightly contributes to the oxidation. A hypothesis would be that octyl ether also perturbates the impermeable monolayer of oleic acid.

Oleic acid and/or stearates coming from iron precursor would form a dense monolayer at the surface of nuclei that would hamper the oxygen diffusion. Reported results show that oleic acid enriched liposomes or low density lipoprotein are thus protected against oxidative modifications[80,81]. This theory is also supported by published works of C. Petit et al. on cobalt NPs[78] where cobalt is protected from oxidation due to a dense coverage of dodecanoic acid on their surface. However, this dodecanoic acid coating prevents NPs from growth through monomer accretion and a further study showed that oxidative protection and growth could be done by choosing the solvent of the synthesis based on its 
interaction with the ligand[82,83]. A solvent with a good affinity with the ligand will disrupt the ligand monolayer on the surface of the NPs, enabling the monomer diffusion towards the nucleus. Such strategy, "ligand-ligand interactions mediated by solvent" has already been reported for the NPs size control[84-86] but is also a parameter controling the composition. Therefore, one may advance that octyl ether may affect the stability of the monolayer and enhances the oxidation kinetics.

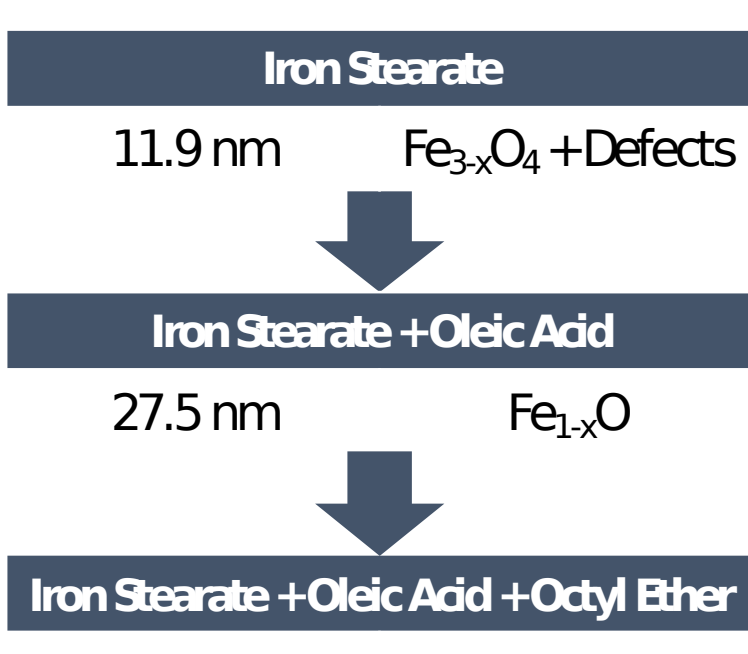

$10.3 \mathrm{~nm}$

$\mathrm{Fe}_{3-\mathrm{x}} \mathrm{O}_{4}$

Figure 8: Summary of the different experimental conditions and of the resulting NPS composition

When experiments are performed at high temperature (Figure 8), since the nucleation step occurs at around $250^{\circ} \mathrm{C}$, the growth step is longer by comparison with the one with low temperature solvent such as OE. A competition between the oxidation and growth rates exists during this growth step.

Synthesis in alkene or alkane solvent at temperature higher than $320^{\circ} \mathrm{C}$, most of the time, leads to core-shell NPs. One may suppose that such solvents do not affect enough the dense oleic acid/stearate monolayer at the surface of the NPs and thus the oxidation is rather limitated: the growth rate is higher than the oxidation ones. 
The fact that a spinel composition with defects is obtained at high temperature $\left(336^{\circ} \mathrm{C}\right)$ may be due to the fact that above $335^{\circ} \mathrm{C}$, considering that oleic acid boiling point is at $360{ }^{\circ} \mathrm{C}$, thermal energy is sufficient to destabilize the shell increasing the oxidation kinetics. If the thermal energy is too important, the ligand will not play its shape-controller role as we observed at reaction temperature above $345{ }^{\circ} \mathrm{C}$. The thermal destabilization of the shell is then more difficult to master than the solvent mediated one as the temperature range is narrow.

OE was shown to enhance the oxidation of NPs at low temperature but at high temperature and mixed with squalane, it reduces the NPs size and does not allow to avoid the formation of core-shell NPs. One hypothesis was that the amount of OE is not sufficient to affect the ligand monolayer as it is observed at low temperature but experiments with octadecylether and DBE confirmed that ether solvents affect the thermal decomposition of iron stearate and favor the nucleation step instead of the growth one but strongly suggested a degradation of the ether solvents at high temperature. This definetly proves that ether solvents are not suitable for synthesizing NPs with mean sizes suitable for magnetic hyperthermia above $14 \mathrm{~nm}$. The fact that the addition of small amounts of DBE in squalane conducts to NPs around $20 \mathrm{~nm}$ and a homogeneous spinel composition but with defects suggested that the decomposition products of DBE in toluene and benzaldehyde (especially benzaldehyde) would destabilize the oleic acid/stearate monolayer at the surface of NPs, allowing the enhancement of the oxidation rate.

To further evidence the impact of the oxidation kinetics over the growth kinetics, we have performed synthesis experiments at lower heating rate to favor the oxidation process of nuclei and slow down the growth of nanoparticles (Figure 9). The precursor was $\mathrm{FeSt}_{3}$ and the solvent was squalane and $1^{\circ} \mathrm{C} / \mathrm{min}$ were applied instead of $5^{\circ} \mathrm{C} / \mathrm{min}$ concerning the heating rate. These conditions led to slightly smaller NPs $(18,6 \pm 2,2 \mathrm{~nm})$ but with an iron spinel composition. On the opposite side, the 
synthesis realized with a heating of $10^{\circ} \mathrm{C} / \mathrm{min}$ led to $\mathrm{Fe}_{1-\mathrm{x}} \mathrm{O}$ NPs with a size of $24.3 \pm$ $3.6 \mathrm{~nm}$. These experiments confirmed again the challenge of controlling the synthesis parameters and mechanisms to master the NPs performance.
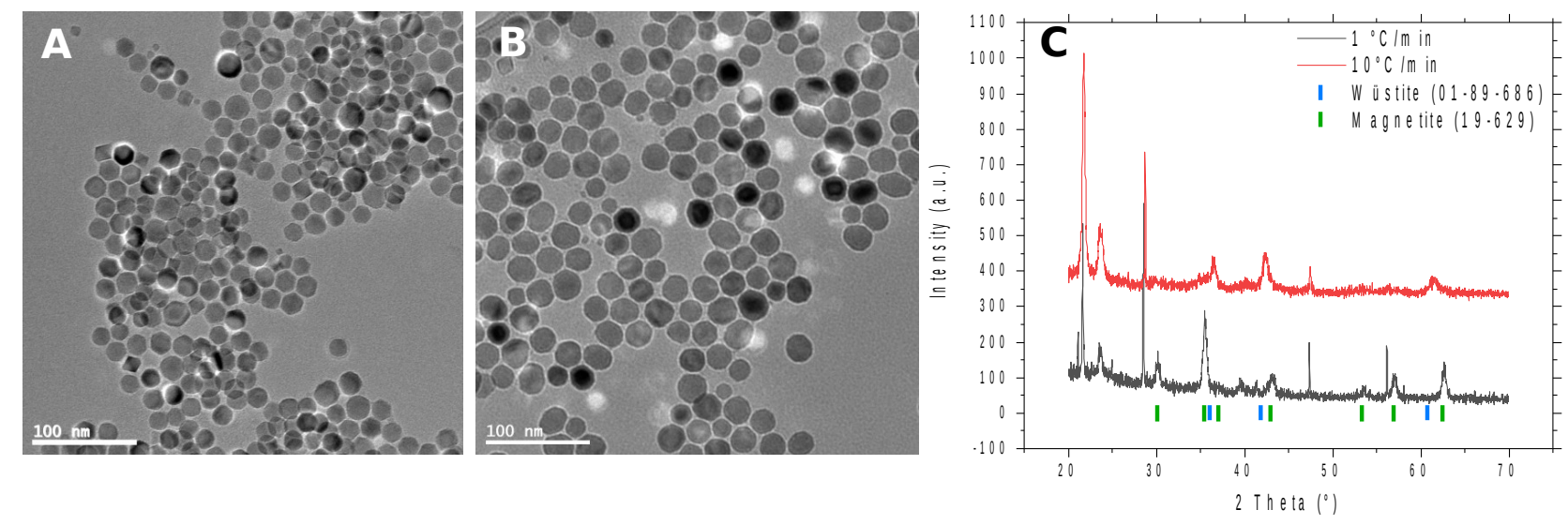

Figure 9. TEM images of NPs synthesized with a heating rate of $\left.1{ }^{\circ} \mathrm{C} / \mathrm{min} \mathrm{A}\right), 10^{\circ} \mathrm{C} / \mathrm{min} \mathrm{B}$ ), XRD of the NPs synthesised with a heating rate of $1^{\circ} \mathrm{C} / \mathrm{min}$ (black line) and $10 \mathrm{C} / \mathrm{min}$ (red line) C).

\section{Conclusion}

The synthesis of iron oxide NPS with mean size and composition suitable for magnetic hyperthermia is currently a challenge as synthesis conditions necessary to reach such high sizes often lead either to core-shell composition or to a spinel composition but with the presence of defects. Both the core-shell composition and the presence of defect may affect the magnetic hyperthermia performance of these NPs.

We demonstrated here that the composition of the nuclei is wüstite. Indeed, Fe (+III) cations in iron stearates are reduced in the nucleation temperature range and this reduction occurs simultaneously with the departure of precursor carboxylate chains. That mechanism is supported by reported works on a decarboxylation catalyzed by ironlll cations leading to a reduction of iron (+III) in iron(+II).

Our experiments demonstrated that the composition of NPs with mean size around $20 \mathrm{~nm}$ depends on the size of $\mathrm{Fe}_{1-\mathrm{x}} \mathrm{O}$ nuclei and the synthesis parameters 
such as the ligands and nature of solvents which will impact the oxydation and growth kinetics of the nuclei. The role of oleic acid is quite complex as it can affect the thermal stability of the precursor, leading to small amounts of nuclei and larger amounts of available precursor at high temperature for the growth process. Therefore, the growth kinetics is fastened by contrast to the oxidation one. Oleic acid molecules also form a dense monolayer, perhaps strengthed by the presence of stearate from iron stearates, at the surface of $\mathrm{Fe}_{1-\mathrm{x}} \mathrm{O}$ nuclei which would hamper the oxygen diffusion. Solvents allowing to affect the stability of the monolayer due to a higher solubility of oleic acid in them (as in octyl ether by contrast to squalane) would favor the oxidation kinetics. It is also possible that $O E$ and DBE/decomposition products substitute oleic acid at the surface of NPs. Experiments in ether solvents demonstrate further that ether sovents are not recommended for high temperature synthesis due to their enhanced reactivity or decomposition.

The synthesis of NPs with a lower heating rate which has slowed down the growth kinetics and thus favored the oxygen diffusion has led to NPs with a homogeneous spinel composition confirming the need to control the growth and oxidation kinetics.

Such studies evidencing solvents and surfactants effects pave the way towards a better control of defect and stoichiometry in oxide nanoparticles.

\section{Acknowledgements}

The Region Alsace, France, and the Labex Chimie des Systemes Complexes, University of Strasbourg, France are gratefully acknowledged for the doctoral fellowship to Geoffrey Cotin. This research project was also co-funded by Labex CSC, Alsace contre le cancer, INCA (project PRTK14, THERAMAG 2014-225) and the 
INTERREG project NANOTRANSMED. The authors thank COST Action RADIOMAG (TD1402), supported by COST (European Cooperation in Science and Technology).

Supporting Information description. Description of IR spectra of iron stearates, XRD patterns of NPs synthesized in different solvents, TEM images of NPs as a function of the SQ/OE ratio; Evolution of NPs diameter with the reaction temperature and Fe-O bands in IR spectra.

\section{References}

[1] A.P. Alivisatos, Semiconductor Clusters, Nanocrystals, and Quantum Dots, Science. 271 (1996) 933-937. https://doi.org/10.1126/science.271.5251.933.

[2] M. Fernández-García, A. Martínez-Arias, J.C. Hanson, J.A. Rodriguez, Nanostructured Oxides in Chemistry: Characterization and Properties, Chem. Rev. 104 (2004) 4063-4104. https://doi.org/10.1021/ cr030032f.

[3] P. Guardia, R. Di Corato, L. Lartigue, C. Wilhelm, A. Espinosa, M. Garcia-Hernandez, F. Gazeau, L. Manna, T. Pellegrino, Water-Soluble Iron Oxide Nanocubes with High Values of Specific Absorption Rate for Cancer Cell Hyperthermia Treatment, ACS Nano. 6 (2012) 3080-3091. https://doi.org/10.1021/nn2048137.

[4] J.-H. Lee, Y.-M. Huh, Y. Jun, J. Seo, J. Jang, H.-T. Song, S. Kim, E.-J. Cho, H.-G. Yoon, J.-S. Suh, J. Cheon, Artificially engineered magnetic nanoparticles for ultra-sensitive molecular imaging, Nat Med. 13 (2007) 95-99. https://doi.org/10.1038/nm1467.

[5] V. Patsula, M. Moskvin, S. Dutz, D. Horák, Size-dependent magnetic properties of iron oxide nanoparticles, Journal of Physics and Chemistry of Solids. 88 (2016) 24-30. https://doi.org/10.1016/j.jpcs.2015.09.008.

[6] G. Cotin, C. Kiefer, F. Perton, D. Ihiawakrim, C. Blanco-Andujar, S. Moldovan, C. Lefevre, O. Ersen, B. Pichon, D. Mertz, S. Bégin-Colin, Unravelling the Thermal Decomposition Parameters for The Synthesis of Anisotropic Iron Oxide Nanoparticles, Nanomaterials. 8 (2018) 881. https://doi.org/10.3390/ nano8110881.

[7] P. Guardia, A. Riedinger, S. Nitti, G. Pugliese, S. Marras, A. Genovese, M.E. Materia, C. Lefevre, L. Manna, T. Pellegrino, One pot synthesis of monodisperse water soluble iron oxide nanocrystals with high values of the specific absorption rate, Journal of Materials Chemistry B. 2 (2014) 4426. https://doi.org/10.1039/c4tb00061g.

[8] A. Walter, C. Billotey, A. Garofalo, C. Ulhaq-Bouillet, C. Lefèvre, J. Taleb, S. Laurent, L. Vander Elst, R.N. Muller, L. Lartigue, F. Gazeau, D. Felder-Flesch, S. Begin-Colin, Mastering the Shape and Composition of Dendronized Iron Oxide Nanoparticles To Tailor Magnetic Resonance Imaging and Hyperthermia, Chem. Mater. 26 (2014) 5252-5264. https://doi.org/10.1021/cm5019025.

[9] G. Muscas, N. Yaacoub, G. Concas, F. Sayed, R.S. Hassan, J.M. Greneche, C. Cannas, A. Musinu, V. Foglietti, S. Casciardi, C. Sangregorio, D. Peddis, Evolution of the magnetic structure with 
chemical composition in spinel iron oxide nanoparticles, Nanoscale. 7 (2015) 13576-13585. https://doi.org/10.1039/C5NR02723C.

[10] M. Niederberger, Nonaqueous Sol-Gel Routes to Metal Oxide Nanoparticles, Acc. Chem. Res. 40 (2007) 793-800. https://doi.org/10.1021/ar600035e.

[11] W. Baaziz, B.P. Pichon, S. Fleutot, Y. Liu, C. Lefevre, J.-M. Greneche, M. Toumi, T. Mhiri, S. Begin-Colin, Magnetic Iron Oxide Nanoparticles: Reproducible Tuning of the Size and NanosizedDependent Composition, Defects, and Spin Canting, J. Phys. Chem. C. 118 (2014) 3795-3810. https://doi.org/10.1021/jp411481p.

[12] K. Borgohain, N. Murase, S. Mahamuni, Synthesis and properties of Cu2O quantum particles, Journal of Applied Physics. 92 (2002) 1292-1297. https://doi.org/10.1063/1.1491020.

[13] S. Tsunekawa, T. Fukuda, A. Kasuya, Blue shift in ultraviolet absorption spectra of monodisperse CeO2-x nanoparticles, Journal of Applied Physics. 87 (2000) 1318-1321. https://doi.org/10.1063/1.372016.

[14] A. TROVARELLI, Catalytic Properties of Ceria and CeO2-Containing Materials, Catalysis Reviews. 38 (1996) 439-520. https://doi.org/10.1080/01614949608006464.

[15] J. Kang, S. Tsunekawa, A. Kasuya, Ultraviolet absorption spectra of amphoteric SnO2 nanocrystallites, Applied Surface Science. 174 (2001) 306-309. https://doi.org/10.1016/S01694332(01)00184-2.

[16] S. Chang, R. Doong, Interband Transitions in Sol-Gel-Derived ZrO2 Films under Different Calcination Conditions, Chem. Mater. 19 (2007) 4804-4810. https://doi.org/10.1021/cm070606n.

[17] V. Ischenko, S. Polarz, D. Grote, V. Stavarache, K. Fink, M. Driess, Zinc Oxide Nanoparticles with Defects, Advanced Functional Materials. 15 (2005) 1945-1954.

https://doi.org/10.1002/adfm.200500087.

[18] Z. Zheng, M. Mounsamy, N. Lauth-de Viguerie, Y. Coppel, S. Harrisson, M. Destarac, C. Mingotaud, M.L. Kahn, J.-D. Marty, Luminescent zinc oxide nanoparticles: from stabilization to slow digestion depending on the nature of polymer coating, Polym. Chem. 10 (2019) 145-154. https://doi.org/10.1039/C8PY01387J.

[19] R. Deshmukh, M. Niederberger, Mechanistic Aspects in the Formation, Growth and Surface Functionalization of Metal Oxide Nanoparticles in Organic Solvents, Chemistry - A European Journal. 23 (2017) 8542-8570. https://doi.org/10.1002/chem.201605957.

[20] A. Heuer-Jungemann, N. Feliu, I. Bakaimi, M. Hamaly, A. Alkilany, I. Chakraborty, A. Masood, M.F. Casula, A. Kostopoulou, E. Oh, K. Susumu, M.H. Stewart, I.L. Medintz, E. Stratakis, W.J. Parak, A.G. Kanaras, The Role of Ligands in the Chemical Synthesis and Applications of Inorganic Nanoparticles, Chem. Rev. 119 (2019) 4819-4880. https://doi.org/10.1021/acs.chemrev.8b00733.

[21] B.P. Pichon, O. Gerber, C. Lefevre, I. Florea, S. Fleutot, W. Baaziz, M. Pauly, M. Ohlmann, C. Ulhaq, O. Ersen, V. Pierron-Bohnes, P. Panissod, M. Drillon, S. Begin-Colin, Microstructural and Magnetic Investigations of Wüstite-Spinel Core-Shell Cubic-Shaped Nanoparticles, Chem. Mater. 23 (2011) 2886-2900. https://doi.org/10.1021/cm2003319.

[22] G. Cotin, C. Kiefer, F. Perton, M. Boero, B. Özdamar, A. Bouzid, G. Ori, C. Massobrio, D. 
Begin, B. Pichon, D. Mertz, S. Begin-Colin, Evaluating the Critical Roles of Precursor Nature and Water Content When Tailoring Magnetic Nanoparticles for Specific Applications, ACS Appl. Nano Mater. 1 (2018) 4306-4316. https://doi.org/10.1021/acsanm.8b01123.

[23] A. Ali, H. Zafar, M. Zia, I. Ul Haq, A.R. Phull, J.S. Ali, A. Hussain, Synthesis, characterization, applications, and challenges of iron oxide nanoparticles, Nanotechnol Sci Appl. 9 (2016) $49-67$. https://doi.org/10.2147/NSA.S99986.

[24] N. Millot, S. Begin-Colin, P. Perriat, G. Le Caër, Structure, Cation Distribution, and Properties of Nanocrystalline Titanomagnetites Obtained by Mechanosynthesis: Comparison with Soft Chemistry, Journal of Solid State Chemistry. 139 (1998) 66-78. https://doi.org/10.1006/jssc.1998.7808.

[25] B. Basly, G. Popa, S. Fleutot, B.P. Pichon, A. Garofalo, C. Ghobril, C. Billotey, A. Berniard, P. Bonazza, H. Martinez, D. Felder-Flesch, S. Begin-Colin, Effect of the nanoparticle synthesis method on dendronized iron oxides as MRI contrast agents, Dalton Trans. 42 (2013) 2146-2157. https://doi.org/10.1039/C2DT31788E.

[26] S. Kossatz, R. Ludwig, H. Dähring, V. Ettelt, G. Rimkus, M. Marciello, G. Salas, V. Patel, F.J. Teran, I. Hilger, High Therapeutic Efficiency of Magnetic Hyperthermia in Xenograft Models Achieved with Moderate Temperature Dosages in the Tumor Area, Pharm Res. 31 (2014) 3274-3288. https://doi.org/10.1007/s11095-014-1417-0.

[27] Kotoulas, Dendrinou-Samara, Angelakeris, Kalogirou, The Effect of Polyol Composition on the Structural and Magnetic Properties of Magnetite Nanoparticles for Magnetic Particle Hyperthermia, Materials. 12 (2019) 2663. https://doi.org/10.3390/ma12172663.

[28] G. Cotin, F. Perton, C. Blanco-Andujar, B. Pichon, D. Mertz, S. Bégin-Colin, Design of Anisotropic Iron-Oxide-Based Nanoparticles for Magnetic Hyperthermia, in: Nanomaterials for Magnetic and Optical Hyperthermia Applications, Elsevier, 2019: pp. 41-60. https://doi.org/10.1016/B978-0-12813928-8.00002-8.

[29] U. Jeong, X. Teng, Y. Wang, H. Yang, Y. Xia, Superparamagnetic Colloids: Controlled Synthesis and Niche Applications, Advanced Materials. 19 (2007) 33-60. https://doi.org/10.1002/adma.200600674.

[30] C. Vichery, I. Maurin, P. Bonville, J.-P. Boilot, T. Gacoin, Influence of Protected Annealing on the Magnetic Properties of $\gamma$-Fe2O3 Nanoparticles, J. Phys. Chem. C. 116 (2012) 16311-16318. https://doi.org/10.1021/jp305069a.

[31] E. Wetterskog, C.-W. Tai, J. Grins, L. Bergström, G. Salazar-Alvarez, Anomalous Magnetic Properties of Nanoparticles Arising from Defect Structures: Topotaxial Oxidation of $\mathrm{Fe}_{1-x} \mathrm{O} \mid \mathrm{Fe}_{3-\delta} \mathrm{O}_{4}$ Core|Shell Nanocubes to Single-Phase Particles, ACS Nano. 7 (2013) 7132-7144.

https://doi.org/10.1021/nn402487q.

[32] S. Disch, E. Wetterskog, R.P. Hermann, A. Wiedenmann, U. Vainio, G. Salazar-Alvarez, L. Bergström, T. Brückel, Quantitative spatial magnetization distribution in iron oxide nanocubes and nanospheres by polarized small-angle neutron scattering, New J. Phys. 14 (2012) 013025. https://doi.org/ 10.1088/1367-2630/14/1/013025.

[33] S. Laurent, D. Forge, M. Port, A. Roch, C. Robic, L. Vander Elst, R.N. Muller, Magnetic Iron Oxide Nanoparticles: Synthesis, Stabilization, Vectorization, Physicochemical Characterizations, and Biological Applications, Chem. Rev. 108 (2008) 2064-2110. https://doi.org/10.1021/cr068445e. 
[34] A. Shavel, L.M. Liz-Marzán, Shape control of iron oxide nanoparticles, Phys. Chem. Chem. Phys. 11 (2009) 3762-3766. https://doi.org/10.1039/B822733K.

[35] L.M. Bronstein, X. Huang, J. Retrum, A. Schmucker, M. Pink, B.D. Stein, B. Dragnea, Influence of Iron Oleate Complex Structure on Iron Oxide Nanoparticle Formation, Chem. Mater. 19 (2007) 36243632. https://doi.org/10.1021/cm062948j.

[36] L.M. Bronstein, J.E. Atkinson, A.G. Malyutin, F. Kidwai, B.D. Stein, D.G. Morgan, J.M. Perry, J.A. Karty, Nanoparticles by Decomposition of Long Chain Iron Carboxylates: From Spheres to Stars and Cubes, Langmuir. 27 (2011) 3044-3050. https://doi.org/10.1021/la104686d.

[37] W. Baaziz, B. Pichon, J.-M. Grenèche, S. Begin-Colin, Effect of environment medium and the in situ formation of precursor on the composition-shape of iron oxide nanoparticles synthesized by thermal decomposition method, CrystEngComm. 20 (2018) 7206-7220. https://doi.org/10.1039/C8CE00875B.

[38] A. Demortière, P. Panissod, B.P. Pichon, G. Pourroy, D. Guillon, B. Donnio, S. Bégin-Colin, Size-dependent properties of magnetic iron oxide nanocrystals, Nanoscale. 3 (2011) 225-232. https://doi.org/10.1039/C0NR00521E.

[39] J. Park, K. An, Y. Hwang, J.-G. Park, H.-J. Noh, J.-Y. Kim, J.-H. Park, N.-M. Hwang, T. Hyeon, Ultra-large-scale syntheses of monodisperse nanocrystals, Nat Mater. 3 (2004) 891-895.

https://doi.org/10.1038/nmat1251.

[40] A. Lak, M. Kraken, F. Ludwig, A. Kornowski, D. Eberbeck, S. Sievers, F.J. Litterst, H. Weller, M. Schilling, Size dependent structural and magnetic properties of $\mathrm{FeO}-\mathrm{Fe} 3 \mathrm{O} 4$ nanoparticles, Nanoscale. 5 (2013) 12286. https://doi.org/10.1039/c3nr04562e.

[41] H.T. Hai, H.T. Yang, H. Kura, D. Hasegawa, Y. Ogata, M. Takahashi, T. Ogawa, Size control and characterization of wustite (core)/spinel (shell) nanocubes obtained by decomposition of iron oleate complex, Journal of Colloid and Interface Science. 346 (2010) 37-42.

https://doi.org/10.1016/j.jcis.2010.02.025.

[42] X. Sun, N. Frey Huls, A. Sigdel, S. Sun, Tuning Exchange Bias in Core/Shell FeO/Fe ${ }_{3} \mathrm{O}_{4}$ Nanoparticles, Nano Letters. 12 (2012) 246-251. https://doi.org/10.1021/nl2034514.

[43] S. Sun, H. Zeng, D.B. Robinson, S. Raoux, P.M. Rice, S.X. Wang, G. Li, Monodisperse MFe2O4 (M = Fe, Co, Mn) nanoparticles, J. Am. Chem. Soc. 126 (2004) 273-279. https://doi.org/10.1021/ja0380852.

[44] S. Sun, H. Zeng, Size-controlled synthesis of magnetite nanoparticles, J. Am. Chem. Soc. 124 (2002) 8204-8205.

[45] F.X. Redl, C.T. Black, G.C. Papaefthymiou, R.L. Sandstrom, M. Yin, H. Zeng, C.B. Murray, S.P. O’Brien, Magnetic, electronic, and structural characterization of nonstoichiometric iron oxides at the nanoscale, J. Am. Chem. Soc. 126 (2004) 14583-14599. https://doi.org/10.1021/ja046808r.

[46] A.N. Shipway, E. Katz, I. Willner, Nanoparticle arrays on surfaces for electronic, optical, and sensor applications, Chemphyschem. 1 (2000) 18-52. https://doi.org/10.1002/14397641(20000804)1:1<18::AID-CPHC18>3.0.CO;2-L.

[47] D.A.J. Herman, S. Cheong-Tilley, A.J. McGrath, B.F.P. McVey, M. Lein, R.D. Tilley, How to choose a precursor for decomposition solution-phase synthesis: the case of iron nanoparticles, Nanoscale. 
7 (2015) 5951-5954. https://doi.org/10.1039/C5NR00718F.

[48] R. Hufschmid, H. Arami, R.M. Ferguson, M. Gonzales, E. Teeman, L.N. Brush, N.D. Browning, K.M. Krishnan, Synthesis of phase-pure and monodisperse iron oxide nanoparticles by thermal decomposition, Nanoscale. 7 (2015) 11142-11154. https://doi.org/10.1039/c5nr01651g.

[49] M.V. Kovalenko, M.I. Bodnarchuk, R.T. Lechner, G. Hesser, F. Schäffler, W. Heiss, Fatty Acid Salts as Stabilizers in Size- and Shape-Controlled Nanocrystal Synthesis: The Case of Inverse Spinel Iron Oxide, J. Am. Chem. Soc. 129 (2007) 6352-6353. https://doi.org/10.1021/ja0692478.

[50] J. Rodríguez-Carvajal, Recent advances in magnetic structure determination by neutron powder diffraction, Physica B: Condensed Matter. 192 (1993) 55-69. https://doi.org/10.1016/09214526(93)90108-I.

[51] A. Le Bail, H. Duroy, J.L. Fourquet, Ab Initio Structure Determination of LiSbWO6 by X ray Powder Diffraction, Materials Research Bulletin. 23 (1988) 447-452. https://doi.org/10.1016/00255408(88)90019-0.

[52] J. Teillet, F. Varret, Unpublished MOSFIT program, (n.d.).

[53] P. Guardia, A. Labarta, X. Batlle, Tuning the Size, the Shape, and the Magnetic Properties of Iron Oxide Nanoparticles, The Journal of Physical Chemistry C. 115 (2011) 390-396.

https://doi.org/10.1021/jp1084982.

[54] T. Hyeon, S.S. Lee, J. Park, Y. Chung, H.B. Na, Synthesis of highly crystalline and monodisperse maghemite nanocrystallites without a size-selection process, J. Am. Chem. Soc. 123 (2001) 1279812801.

[55] S.G. Kwon, Y. Piao, J. Park, S. Angappane, Y. Jo, N.-M. Hwang, J.-G. Park, T. Hyeon, Kinetics of monodisperse iron oxide nanocrystal formation by "heating-up” process, J. Am. Chem. Soc. 129 (2007) 12571-12584. https://doi.org/10.1021/ja074633q.

[56] A. Lassenberger, T.A. Grünewald, P.D.J. van Oostrum, H. Rennhofer, H. Amenitsch, R. Zirbs, H.C. Lichtenegger, E. Reimhult, Monodisperse Iron Oxide Nanoparticles by Thermal Decomposition: Elucidating Particle Formation by Second-Resolved in Situ Small-Angle X-ray Scattering, Chem. Mater. 29 (2017) 4511-4522. https://doi.org/10.1021/acs.chemmater.7b01207.

[57] B. Chaudret, Organometallic approach to nanoparticles synthesis and self-organization, Comptes Rendus Physique. 6 (2005) 117-131. https://doi.org/10.1016/j.crhy.2004.11.008.

[58] F. Dumestre, B. Chaudret, C. Amiens, P. Renaud, P. Fejes, Superlattices of iron nanocubes synthesized from Fe[N(SiMe3)2]2, Science. 303 (2004) 821-823.

https://doi.org/10.1126/science.1092641.

[59] C.C.R. Sutton, G. da Silva, G.V. Franks, Modeling the IR Spectra of Aqueous Metal Carboxylate Complexes: Correlation between Bonding Geometry and Stretching Mode Wavenumber Shifts, Chem. Eur. J. 21 (2015) 6801-6805. https://doi.org/10.1002/chem.201406516.

[60] G.B. Deacon, R.J. Phillips, Relationships between the carbon-oxygen stretching frequencies of carboxylato complexes and the type of carboxylate coordination, Coordination Chemistry Reviews. 33 (1980) 227-250. https://doi.org/10.1016/S0010-8545(00)80455-5. 
[61] K. Nakamoto, Applications in Inorganic Chemistry, in: Infrared and Raman Spectra of Inorganic and Coordination Compounds, John Wiley \& Sons, Inc., Hokoken, 2008: pp. 149-354. https://doi.org/10.1002/9780470405840.ch2.

[62] V. Zelenák, Z. Vargová, K. Györyová, Correlation of infrared spectra of zinc(II) carboxylates with their structures., Spectrochim Acta A Mol Biomol Spectrosc. 66 (2007) 262-272. https://doi.org/10.1016/j.saa.2006.02.050.

[63] E.G. Palacios, G. Juárez-López, A.J. Monhemius, Infrared spectroscopy of metal carboxylates: II. Analysis of Fe(III), Ni and Zn carboxylate solutions, Hydrometallurgy. 72 (2004) 139-148. https://doi.org/10.1016/S0304-386X(03)00137-3.

[64] G. Cotin, Nouvelles stratégies vers la synthèse de nanoparticules magnétiques multifonctionnelles innovantes combinant imagerie par IRM et/ou thérapie par hyperthermie magnétique, (n.d.) 344.

[65] B. Özdamar, A. Bouzid, G. Ori, C. Massobrio, M. Boero, First-Principles Study of Dissociation Processes for the Synthesis of Fe and Co Oxide Nanoparticles, J. Chem. Theory Comput. 14 (2018) 225235. https://doi.org/10.1021/acs.jctc.7b00869.

[66] R. Davis, H.P. Schultz, Studies of Thermal Decarboxylation of Iron Carboxylates. I. Preparation of Symmetrical Aliphatic Ketones ${ }^{1,2}$, The Journal of Organic Chemistry. 27 (1962) 854-857. https://doi.org/10.1021/jo01050a039.

[67] L.J. Gooßen, P. Mamone, C. Oppel, Catalytic Decarboxylative Cross-Ketonisation of Aryl- and Alkylcarboxylic Acids using Magnetite Nanoparticles, Advanced Synthesis \& Catalysis. 353 (2011) 5763. https://doi.org/10.1002/adsc.201000429.

[68] N. Pérez, F. López-Calahorra, A. Labarta, X. Batlle, Reduction of iron by decarboxylation in the formation of magnetite nanoparticles, Physical Chemistry Chemical Physics. 13 (2011) 19485. https://doi.org/10.1039/c1cp20457b.

[69] S. Pawsey, K. Yach, J. Halla, L. Reven, Self-Assembled Monolayers of Alkanoic Acids: A Solid-State NMR Study, Langmuir. 16 (2000) 3294-3303. https://doi.org/10.1021/la991273e.

[70] K.E. Gilbert, J.J. Gajewski, Coal liquefaction model studies: free radical chain decomposition of diphenylpropane, dibenzyl ether, and phenethyl phenyl ether via .beta.-scission reactions, J. Org. Chem. 47 (1982) 4899-4902. https://doi.org/10.1021/jo00146a016.

[71] S.C. Moldoveanu, Pyrolysis of Organic Molecules: Applications to Health and Environmental Issues, Elsevier, Amsterdam, 2009.

[72] R.L. Elder, Final Report on the Safety Assessment of Squalane and Squalene, Journal of the American College of Toxicology. 1 (1990) 37-56. https://doi.org/10.3109/10915818209013146.

[73] S.C. Moldoveanu, Pyrolysis of Ethers, in: Pyrolysis of Organic Molecules, Elsevier, 2019: pp. 279-310. https://doi.org/10.1016/B978-0-444-64000-0.00005-6.

[74] T.J. Daou, J.M. Grenèche, G. Pourroy, S. Buathong, A. Derory, C. Ulhaq-Bouillet, B. Donnio, D. Guillon, S. Begin-Colin, Coupling Agent Effect on Magnetic Properties of Functionalized MagnetiteBased Nanoparticles, Chemistry of Materials. 20 (2008) 5869-5875. https://doi.org/10.1021/cm801405n.

[75] S. Mourdikoudis, R.M. Pallares, N.T.K. Thanh, Characterization techniques for nanoparticles: 
comparison and complementarity upon studying nanoparticle properties, Nanoscale. 10 (2018) 1287112934. https://doi.org/10.1039/C8NR02278J.

[76] W. Shi, H. Zeng, Y. Sahoo, T.Y. Ohulchanskyy, Y. Ding, Z.L. Wang, M. Swihart, P.N. Prasad, A General Approach to Binary and Ternary Hybrid Nanocrystals, Nano Lett. 6 (2006) 875-881. https://doi.org/10.1021/nl0600833.

[77] F.J. Douglas, D.A. MacLaren, M. Murrie, A study of the role of the solvent during magnetite nanoparticle synthesis: tuning size, shape and self-assembly, RSC Adv. 2 (2012) 8027-8035. https://doi.org/10.1039/C2RA20494K.

[78] I. Lisiecki, M.P. Pileni, Synthesis of Well-Defined and Low Size Distribution Cobalt Nanocrystals: The Limited Influence of Reverse Micelles, Langmuir. 19 (2003) 9486-9489. https://doi.org/10.1021/la0301386.

[79] P. Tancredi, P.C.R. Rojas, O. Moscoso-Londoño, U. Wolff, V. Neu, C. Damm, B. Rellinghaus, M. Knobel, L.M. Socolovsky, Synthesis process, size and composition effects of spherical Fe3O4 and FeO@Fe3O4 core/shell nanoparticles, New J. Chem. 41 (2017) 15033-15041. https://doi.org/10.1039/C7NJ02558K.

[80] S. Parthasarathy, J.C. Khoo, E. Miller, J. Barnett, J.L. Witztum, D. Steinberg, Low density lipoprotein rich in oleic acid is protected against oxidative modification: implications for dietary prevention of atherosclerosis., PNAS. 87 (1990) 3894-3898. https://doi.org/10.1073/pnas.87.10.3894.

[81] C. Lee, J. Barnett, P.D. Reaven, Liposomes enriched in oleic acid are less susceptible to oxidation and have less proinflammatory activity when exposed to oxidizing conditions, J. Lipid Res. 39 (1998) $1239-1247$.

[82] S. Costanzo, Synthèse, caractérisation et spectroscopie de nanoparticules de Co et (coeur) Co / (coquille) CoO auto-organisées, Université Pierre et Marie Curie, 2017.

[83] S. Costanzo, G. Simon, J. Richardi, Ph. Colomban, I. Lisiecki, Solvent Effects on Cobalt Nanocrystal Synthesis-A Facile Strategy To Control the Size of Co Nanocrystals, J. Phys. Chem. C. 120 (2016) 22054-22061. https://doi.org/10.1021/acs.jpcc.6b07293.

[84] A. Widmer-Cooper, P.L. Geissler, Ligand-Mediated Interactions between Nanoscale Surfaces Depend Sensitively and Nonlinearly on Temperature, Facet Dimensions, and Ligand Coverage, ACS Nano. 10 (2016) 1877-1887. https://doi.org/10.1021/acsnano.5b05569.

[85] Y. Yin, A.P. Alivisatos, Colloidal nanocrystal synthesis and the organic-inorganic interface, Nature. 437 (2005) 664-670. https://doi.org/10.1038/nature04165.

[86] M.-P. Pileni, The role of soft colloidal templates in controlling the size and shape of inorganic nanocrystals, Nat Mater. 2 (2003) 145-150. https://doi.org/10.1038/nmat817. 


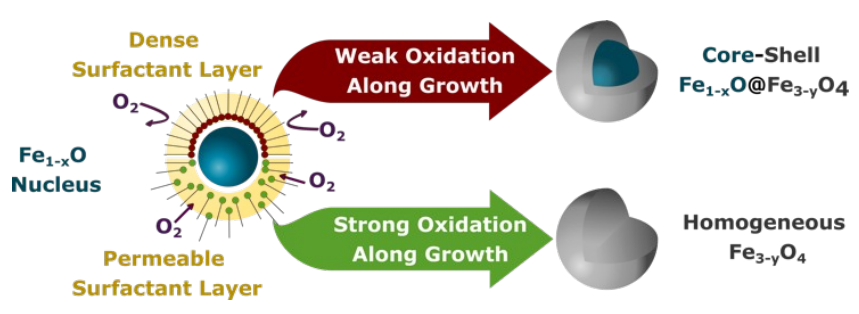

Graphical abstract: impact of solvent mediated ligand-ligand interaction and of competition between oxidation and growth kinetics of $\mathrm{FeO}$ nuclei on the stochiometry and defect in iron oxide nanoparticles 